\title{
FERTILIDADE DE GEMAS E QUALIDADE DE CACHOS DE CULTIVARES DE UVAS APIRÊNICAS TRATADAS COM FITORREGULADORES
}

\section{VALTEMIR GONÇALVES RIBEIRO}

Engenheiro Agrônomo

Orientador: Prof. Dr. JOÃO ALEXIO SCARPARE FILHO

Tese apresentada à Escola Superior de Agricultura "Luiz de Queiroz", Universidade de São Paulo, para obtenção do título de Doutor em Agronomia, Área de Concentração: Fitotecnia.

PIRACICABA

Estado de São Paulo - Brasil

Maio - 2002 


\section{Dados Internacionais de Catalogação na Publicação (CIP) DIVISÃO DE BIBLIOTECA E DOCUMENTAÇĀO - ESALO/USP}

\section{Ribeiro, Valtemir Gonçalves}

Ferwilidade de gemas e qualidade de cachos de cultivares de uvas apirênicas tratadas com fitorreguladores / Valtemir Gonçalves Ribeiro. - - Piracicaba, 2002.

$58 \mathrm{p}$.

Tese (doutorado) - Escola Superior de Agricultura Luiz de Queiroz, 2002.

Bibliografia.

1. Floração 2. Frutificação 3. Práticas culturais (fitotecnia) 4. Regulador de crescimento vegetal 5. Uva I. Título

$\operatorname{CDD} 634.8$ 


\section{DEDICATÓRIA}

À Lívia, minha filha e Valkiria, minha irmã 


\section{AGRADECIMENTOS}

Aos que compartilharam na realização deste trabalho; porém, destaque especial são destinados àqueles que estiveram mais envolvidos:

Ao Prof. Dr. João Aléxio Scarpare Filho (ESALQ/USP) pela orientação, conduta e amizade durante todo o transcorrer do curso;

Ao Pesquisador Dr. Umberto Almeida Camargo (Embrapa Uva e Vinho) e colaboradores, cujos trabalhos em manejo com cultivares de uvas apirênicas utilizando citocininas, auxinas e cycocel, na Estação Experimental de Jales, serviram de referências para os trabalhos de Tese;

Ao Prof. Dr. Jorge Nilton Nabib Chalfun (UFLA), responsável pelo meu início nesta caminhada pela Viticultura, ainda quando estudante pela UFLA;

Ao senhor Antonio Portronieri, em cuja propriedade foram executados os experimentos;

E, aos amigos do Departamento de Produção Vegetal: Bete, D. Helena, Célia, Luciane, Erreinaldo, David e Aparecido ficam meus agradecimentos pelos auxílios dispensados. 


\section{SUMÁRIO}

Página

LISTA DE SIGLAS, ABREVIATURAS OU SÍMBOLOS.......................... vii CURRÍCULUM VITAE................................................................. viii

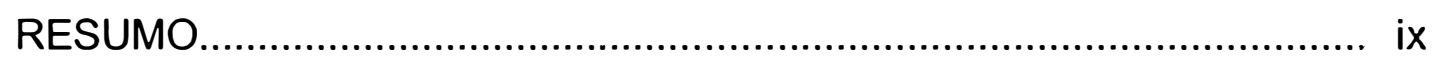

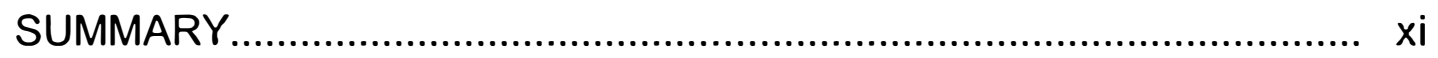

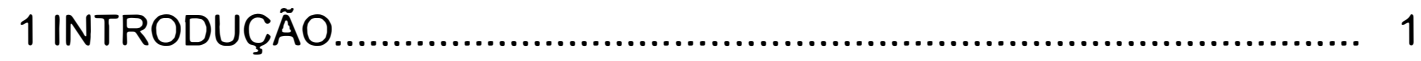

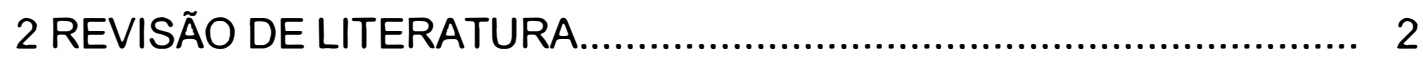

2.1 Origem, classificação e cultivares............................................... 2

2.2 Regiões vitivinicolas no Brasil e mercados.................................. 6

2.3 Aspectos hormonais do florescimento e sobre a qualidade de

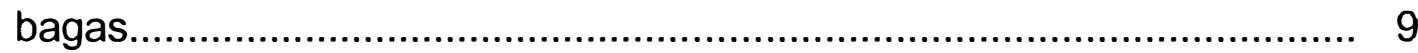

3 CRESCIMENTO DE BAGAS DE UVAS APIRÊNICAS (Vitis vinifera L.) TRATADAS COM CPPU E GA

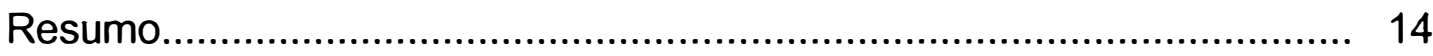

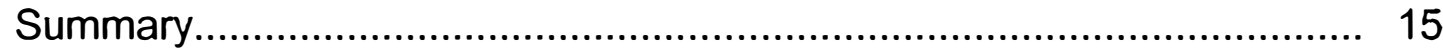




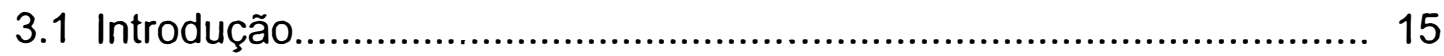

3.2 Material e Métodos.................................................................. 18

3.3 Resultados e Discussão.......................................................... 20

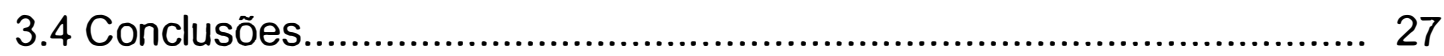

4 FERTILIDADE DE GEMAS EM CULTIVARES DE UVAS APIRENNICAS TRATADAS COM BENZYLADENINA E CYCOCEL........... 28

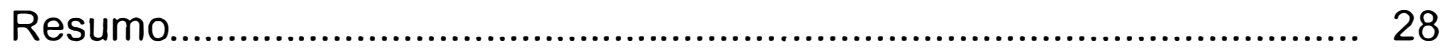

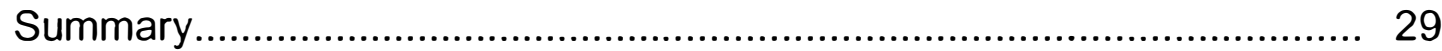

4.1 Introdução......................................................................... 29

4.2 Material e Métodos................................................................ 31

4.3 Resultados e Discussão............................................................... 34

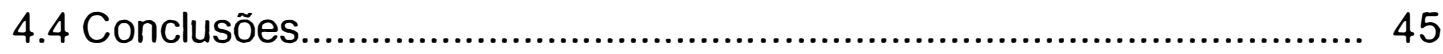

5 CONCLUSÕES GERAIS.......................................................... 46

REFERÊNCIAS BIBLIOGRÁFICAS........................................... 48 


\section{LISTA DE SIGLAS, ABREVIATURAS OU SÍMBOLOS}

CCC - cycocel, chlormequat, cloreto de clorocolina

CPPU - forchlorfenuron

$\mathrm{GA}_{3}$ - ácido giberélico

$\mathrm{mg} \cdot \mathrm{L}^{-1}$ - miligramas por litro

$\mu \mathrm{M}$ - micro molar 


\section{CURRICULUM VITAE}

Engenheiro Agrônomo (1992) e Mestre (1997) pela Universidade Federal de Lavras/UFLA.

De julho/97 à dez/98 foi bolsista do CNPq pelo Programa BIOEX, sob coordenação da Embrapa Uva e Vinho (CNPUV)/Estação Experimental de Jales, estando vinculado ao projeto "Desenvolvimento da viticultura para a região de Jales". 


\title{
FERTILIDADE DE GEMAS E QUALIDADE DE CACHOS DE CULTIVARES DE UVAS APIRÊNICAS TRATADAS COM FITORREGULADORES
}

\author{
Autor: VALTEMIR GONÇALVES RIBEIRO \\ Orientador: Prof. Dr. JOÃO ALEXIO SCARPARE FILHO
}

\section{RESUMO}

As cultivares de uvas apirênicas, em via de regra, possuem tamanhos de bagas reduzidas, necessitando de ajustes no manejo para a melhoria da qualidade dos cachos, sendo a aplicação de reguladores de crescimento um dos tratamentos mais eficazes. Objetivou-se, com um primeiro experimento avaliar os efeitos do Forchlorfenuron (CPPU: 0 e $10 \mathrm{mg}^{-1} \mathrm{~L}^{-1}$ ) mais o Ácido giberélico $\left(\mathrm{GA}_{3}: 0,25,50,75\right.$ e $\left.100 \mathrm{mg} \cdot \mathrm{L}^{-1}\right)$ para a melhoria da qualidade dos cachos das cultivares Vitis vinifera (L.) Centennial seedless, Flame seedless e Thompson seedleess. As características avaliadas foram o comprimento, largura e peso de bagas. A aplicação de $100 \mathrm{mg} \cdot \mathrm{L}^{-1} \mathrm{de} \mathrm{GA}_{3}$ foi a mais responsiva para a 'Centennial seedless'; sendo para a 'Flame seedless' e 'Thompson seedless' esta mesma concentração de $\mathrm{GA}_{3}$, porém adicionada a $10 \mathrm{mg} \cdot \mathrm{L}^{-1}$ de CPPU. Houve redução nos teores de sólidos solúveis totais do mosto das cultivares pelo efeito da aplicação com os fitorreguladores, retardando o período da colheita. Um segundo experimento foi montado objetivando-se verificar o efeito do $\operatorname{CCC}\left(0,500\right.$ e $\left.1.000 \mathrm{mg} \cdot \mathrm{L}^{-1}\right)$ combinado com a BA $(500 \mu \mathrm{M})$, seguidos de 
uma segunda época de aplicação de $\operatorname{CCC}\left(0,50.000\right.$ e $\left.100.000 \mathrm{mg} \cdot \mathrm{L}^{-1}\right)$, para a melhoria da fertilidade de gemas das cultivares Vitis vinifera (L.) 'Flame seedless' e 'Thompson seedless'. Para a 'Flame seedless', CCC a 517,29 mg. $\mathrm{L}^{-1}$ mais BA, aplicados a 105 dias do início da brotação, promoveram a fertilidade de $54,45 \%$ das gemas, e houve uma melhor distribuição das gemas férteis ao longo das varas. 


\title{
FRUIT BUDS OF SEEDLESS TABLE GRAPES AND CLUSTER QUALITY TREATY WITH GROWTH REGULATORS
}

\author{
Author: VALTEMIR GONÇALVES RIBEIRO \\ Adviser: Prof. Dr. JOÃO ALEXIO SCARPARE FILHO
}

\section{SUMMARY}

The seedless grapes, always have decrease in berry size, requiring managements to increase cluster quality. The spray with growth regulators is the treatment preferentially to enlarge berry size. The objective of first work was to derermine the effects of Forchlorfenuron (CPPU: 0 e $10 \mathrm{mg} \cdot \mathrm{L}^{-1}$ ) associated with Giberelic acid $\left(\mathrm{GA}_{3}: 0,25,50,75\right.$ e $\left.100 \mathrm{mg} \cdot \mathrm{L}^{-1}\right)$ interaction about increase in berry size on first harvest cycle of the seedless Centennial, Flame and Thompson table grapes. Higher berry length, breadth and weigth were in average obtaind at $100 \mathrm{mg} . \mathrm{L}^{-1} \mathrm{GA}_{3}$ for 'Centennial seedless'; and $100 \mathrm{mg} \cdot \mathrm{L}^{-1}$ $\mathrm{GA}_{3}$ in associeted with $10 \mathrm{mg} \cdot \mathrm{L}^{-1} \mathrm{CPPU}$ for the cultivars Flame seedless and Thompson seedless, and were delayed fruits maturation in terms of soluble solids content of all table grape cultivars. An second experiment was realized with the objetive of study the effects of application of levels chlormequat $(0,500$ and $\left.1.000 \mathrm{mg} \cdot \mathrm{L}^{-1}\right)$ in combination with single level of benzyladenine $(500 \mu \mathrm{M})$, followed by application of others levels chlormequat $(0,50.000$ and 100.000 $\mathrm{mg} \cdot \mathrm{L}^{-1}$ ) on the rate inflorescence formation during the second production cycle in 
Vitis vinifera (L.) 'Flame seedless' and 'Thompson seedless'. Chlormequat $\left(517,29 \mathrm{mg} \cdot \mathrm{L}^{-1}\right)$ in combination with benzyladenine promoted inflorescence formation of the 'Flame seedless' $(54,45 \%)$ when applicated during the differentiation of the buds with 105 days after of the formation prune, and showed a distribution of the fertile buds in long of branches, which were cutting with twenty buds. 


\section{INTRODUÇÃO}

A produção de uvas finas de mesa no Brasil está embasada nas cultivares de uvas com sementes, com destaque para a 'Itália' e suas mutações 'Rubi' e 'Benitaka'. Frente à crescente demanda interna e para exportação de uvas apirênicas, ajustes no sistema de manejo objetivando uma melhor adaptação das cultivares apirênicas já introduzidas tornam-se necessários, pois, em via de regra, essas cultivares apresentam excesso de vigor vegetativo, baixa fertilidade de gemas e de qualidade de cachos, resultando numa baixa produção (Camargo et al., 1996; Camargo, 1998).

O uso de fitorreguladores tem sido utilizado em várias espécies, para determinadas finalidades. Em videira, giberelinas são amplamente utilizadas para promover o crescimento de bagas e melhoria da qualidade de cachos, tanto em cultivares com ou sem sementes.

O vigor vegetativo de certas cultivares indica uma relação antagônica com a diferenciação das suas gemas para flores, provavelmente pela ação de fitormônios predominantemente ligados ao crescimento vegetativo. $O$ equilíbrio endógeno de fitormônios, supostamente envolvidos nos processos de floração da videira, via tratamentos com fitorreguladores, foi o principal objetivo deste trabalho, e seus efeitos sobre o crescimento de bagas apirências.

Estudou-se a fertilidade de gemas dos Vitis vinifera (L.) 'Flame seedless' e 'Thompson seedless' tratadas com Cycocel (CCC) juntamente com a Benzyladenina (BA), e do forchlorfenuron (CPPU) com o ácido giberélico $\left(\mathrm{GA}_{3}\right)$ sobre o crescimento de bagas das cultivares Vitis vinifera (L.) Centennial seedless, Flame seedless e Thompson seedless. 


\section{REVISÃO DE LITERATURA}

\subsection{Origem, classificação e cultivares}

A videira teve origem no período terciário, anteriormente ao homem; contudo, seu cultivo foi verificado somente durante a era neolítica (6000 a 5000 a.C.), constatando-se a distribuição da Vitis vinifera L. pela Europa há 7500 a 2500 anos atrás, sendo provavelmente a Groelândia o centro paleontológico de origem da videira (Souza, 1969).

Após o degelo glacial, atribuída ao período quaternário, videiras encontradas em regiões cujos invernos eram menos rigorosos (americano, europeu e o asiático-ocidental) foram se distribuindo no globo terrestre.

No centro americano formaram-se as atuais espécies americanas: V. labrusca, V. rotundifolia, V. rupestris, etc.; no centro asiático-ocidental, ao sul do mar negro, região do Cáucaso, as espécies de $V$. vinifera caucásica; e, no centro europeu, o V. vinifera silvestris (Souza, 1969), disseminando-se com o passar do tempo para as regiões adjacentes. Segundo Alvarenga et al. (1998), as espécies da secção Euvitis podem ser classificadas via agrupamentos geográficos: Euvitis americanas, Euvitis da Ásia Oriental, e Euvitis Européias e Ásia Ocidental.

A família vitácea possui 10 gêneros, entre os quais o Vitis (Tournef) L., que se divide em dois sub-gêneros: Muscadínea PLANCH, $2 n=40$, com três espécies; e o Euvitis PLANCH (videiras verdadeiras), 2n=38, com 59 espécies. A videira européia (V. vinifera L.), segundo Alvarenga et al. (1998), é a mais 
antiga espécie cultivada pelo homem, sendo também aquela de maior importância econômica para o mundo.

Pelos milhões de anos de existência, a videira acumulou uma enorme variabilidade genética, existindo atualmente acima de 240.000 espécies já classificadas e catalogadas (Toda, 1991).

A principal limitação tecnológica da viticultura tropical refere-se à disponibilidade de cultivares alternativas. Praticamente toda a viticultura tropical brasileira fundamenta-se na cultivar Itália, que tem boa aceitação no mercado interno e também tem sido exportada com sucesso.

Há duas formas básicas possiveis de se tentar resolver o problema, seja pela criação de novas cultivares ou pela adaptação de cultivares aos nossos sistemas de cultivo, via práticas de manejo.

Os trabalhos de melhoramento desenvolvidos até o momento por pesquisadores como Souza (1969) e Santos Neto $(1955$; 1971) para obtenção de cultivares de uva de mesa estiveram fundamentados em variedades com sementes.

Citam-se: 'JD 874'- plantas de bom vigor e com resistência média a doenças; 'Soraya'- planta vigorosa e com certo grau de resistência a doenças criptogâmicas, contudo, possui bagas que racham com facilidade no periodo chuvoso; 'Patrícia'- planta muito suscetível ao mildio, mas com resistência satisfatória a podridões; 'Yole'- plantas vigorosas, dotadas de relativa resistência e livres de rachaduras e podridões (Terra et al., 1998) e 'Dona Zilá' e 'Tardia de Caxias', cultivares americanas criadas pela Embrapa Uva e Vinho (Camargo et al., 1994).

Algumas dessas cultivares chegaram a ser plantadas em áreas comerciais do Vale do Gorotuba, no Norte de Minas Gerais, mas devido a problemas qualitativos da uva não tiveram maior expansão (Pommer, 1993).

O melhoramento para apirenia tem sido praticado desde o século passado, com o uso de genótipos estenoespermocárpicos como macho em cruzamentos com fêmeas produtoras de frutos com sementes (Bordelon et al., 1994). Desta forma, o método tradicional de melhoramento de uvas apirênicas 
requer o uso de progenitor feminino pirênico para garantir a obtenção de sementes na próxima geração, sendo os genótipos utilizados como doadores de pólen. Esta metodologia tem baixa eficiência, uma vez que $1 / 4$ da progênie, em média, tem evidenciado o caráter pirênico (Spiegel-Roy et al., 1985).

Técnicas para o desenvolvimento de uvas apirênicas estão sendo adaptadas e realizadas com sucesso no Brasil, com uma eficiência da ordem de $14 \%$, e esforços têm sido feitos para desenvolver protocolos alternativos com vistas a aumentar o número de embriões resgatados (Oliveira \& Camargo, 1993; Amaral et al., 1998).

Pommer et al. (1992) conseguiram a supressão de sementes da cultivar Itália através de tratamentos com estreptomicina, contudo, tal técnica se praticada por longos períodos e escalas, provavelmente traria problemas aos ecossistemas, sobretudo, para o homem.

Quanto às cultivares de uva sem sementes, praticamente todas as cultivares do mundo descendem da 'Corinto', possuidora de frutos pretos, pequenos e totalmente sem sementes, originados por partenocarpia; e da 'Sultanina' ou 'Thompson seedless', que tem frutos brancos, ovais, maiores que os da 'Corinto', originados por estenoespermocarpia.

Embora as flores da 'Sultanina' sejam hermafroditas perfeitas, com pólen viável e necessitando da polinização para a produção dos frutos, os óvulos são afetados no início do desenvolvimento, originando sementes rudimentares ou abortivas (Pommer, 1993).

Santos Neto $(1955 ; 1971)$ criou diversas cultivares de uvas de mesa apirênicas para as regiões tropicais do Brasil, bem como alguns dos principais porta-enxertos utilizados para as regiões tropicais brasileiras: IAC313 'Tropical'; IAC572 'Jales' e o IAC766 'Campinas', que tem se demonstrado como uma boa opção para a enxertia de cultivares vigorosas apirênicas no Vale do São Francisco (Camargo, 1998).

- Reddy \& Prakash (1990) avaliando ao microscópio gemas de 'Anab-e-Shahi', sobre quatro porta-enxertos, antes da época da poda, 
verificaram variações na posição da gema fértil, em relação aos diferentes portaenxertos utilizados.

Existem muitas cultivares potencialmente exploráveis no Brasil. A cultivar Maria (IAC 514-6) é vigorosa, porém apresenta baixa resistência às moléstias, sobretudo ao oídio, adere bem ao pedicelo e necessita também de tratos especiais. A 'Paulistinha'(IAC 457-11) possui pequena e média resistência ao transporte e igualmente à 'Maria', tem boa aderência ao pedicelo.

A 'Fantasy seedless' ('Fantasia') e 'Crimson seedless' ('Ruiva'), são cultivares introduzidas pelo IAC, e segundo Pommer et al. (1999) têm demonstrado elevado potencial produtivo no estado de São Paulo, além de excelentes características comerciais.

A 'Vênus' é uma cultivar vigorosa e produtiva, foi introduzida pela Embrapa Uva e Vinho, possui bagas pretas com acentuada concentração de pruina, embora sem sementes, apresentam traços variados em tamanho, e os cachos são irregulares e compactos (Camargo \& Mandelli, 1993), existindo alguns lotes comerciais em Bento Gonçalves (Terra et al. 1998) e no Noroeste Paulista.

Para as regiões tropicais também têm sido obtidos resultados positivos através da introdução e avaliação de cultivares, bem como pelo desenvolvimento e adaptação de tecnologias específicas de manejo (Camargo et al., 1997).

A 'Centennial seedless', também introduzida pelo IAC, quando enxertada na Região Noroeste do Estado de São Paulo, demonstra razoável vigor (Terra et al., 1998), entretanto, possui baixa aderência ao pedicelo e quando a maturação ocorre em periodos de alta temperatura, a coloração da uva é prejudicada por manchas pardacentas que surgem durante esta fase, tornando-a não recomendável para o Vale do São Francisco (Camargo, 1998).

A 'Flame seedless', obtido pelo Departamento de Agricultura dos Estados Unidos, em Fresno, Califórnia, é tido como promissor para a Região do Vale do São Francisco (BAPE), chegando a produzir em torno de 18 ton/ha; seus cachos são médios, cônicos, moderadamente soltos, e as bagas são 
pequenas, arredondadas, avermelhadas, textura firme, sabor neutro e doce (Camargo et al., 1997).

A 'Thompson seedless', quando cultivado em região de intenso calor torna-se produtivo, sendo uma cultivar com pouca adaptação aos nossos sistemas tropicais de cultivo. Tem cachos grandes, alados, cilíndrico-alongados e compactos, e as bagas são esverdeadas ou levemente douradas quando maduras, textura firme, sabor neutro e doce (Camargo et al., 1997; Terra et al., 1998; Camargo, 1998; Pommer, 1998).

\subsection{Regiões vitivinicolas no Brasil ${ }^{1}$ e mercados}

A Viticultura brasileira foi iniciada provavelmente em 1532, na Capitania de São Vicente, hoje São Paulo, através de Martin Afonso de Souza, via introduções de Vitis vinifera procedentes da Espanha e Portugal. Atualmente, ocupa uma área aproximada de $60 \mathrm{mil}$ ha. Situa-se entre o paralelo $30^{\circ} \mathrm{S}$, no Estado do Rio Grande do Sul, e o paralelo 9 `S, na Região Nordeste do País.

No início do século XIX foram importadas uvas americanas da América do Norte, sendo a 'Isabel' aquela que alavancou a viticultura comercial nos estados do Rio Grande do Sul e São Paulo; sendo posteriormente substituída no início do século XX pelas cultivares Niagara Rosada e Seibel 2.

A viticultura tropical, propriamente dita, desenvolveu-se com 0 plantio de vinhedos comerciais de uva de mesa na Região do Vale do São Francisco, Norte do Paraná e Noroeste do Estado de São Paulo, respectivamente, a partir das décadas de 1960, 1970 e 1980.

\footnotetext{
${ }^{1}$ Adaptado de Camargo, U.A. In: IV Seminário Internacional de Viticultura e Enologia Tropical. Maracaibo, Venezuela, 26-31 de maio de 1997.
} 
As principais regiões vitivinicolas brasileiras são:

a) Região da Serra Gaúcha (Lat. $29^{\circ} \mathrm{S}$; Long. $51^{\circ} \mathrm{W}$ ), onde a maior parte da uva colhida é americana (80 \%) e destinada para a elaboração de vinhos, sucos e outros derivados;

b) Região do Vale do Rio do Peixe, no estado de Santa Catarina (Lat. $27^{\circ} \mathrm{S}$; Long. $51^{\circ} \mathrm{W}$ ), onde a produção é quase toda voltada para vinhos e sucos, igualmente ao que ocorre na Região da Serra Gaúcha, ocupando a cultivar Isabel $75 \%$ da área dos vinhedos;

c) Região Leste do Estado de São Paulo (Lat. $23^{\circ} \mathrm{S}$; Long. $47^{\circ} \mathrm{W}$ ), onde $77 \%$ da área cultivada corresponde à 'Niagara Rosada';

d) Região Norte do Paraná (Lat. $23^{\circ} \mathrm{S}$; Long. $51^{\circ} \mathrm{W}$ ), caracterizada pela produção de uvas finas de mesa, com destaques para 'Itália' e suas mutações 'Rubi' e 'Benitaka';

e) Região Noroeste do Estado de São Paulo (Lat. $20^{\circ} \mathrm{S}$; Long. $50^{\circ} \mathrm{W}$ ), sendo também a 'Itália', 'Rubi' e 'Benitaka' as bases da viticultura da região;

f) Região do Vale do São Francisco (Lat. $9^{\circ} \mathrm{S}$; Long. $40^{\circ} \mathrm{W}$ ), nos estados da Bahia e Pernambuco, sendo esta a principal região vitícola tropical do Brasil, onde predomina o cultivo da 'Itália', e em segundo lugar a 'Piratininga', e em menor escala 'Red Globe' e Christmas Rose', assim como 'Cabernet Sauvignon', 'Syrah', 'Chardonnay' e 'Chenin Blanc' para elaboração de vinhos e 'Alicante Bouschet' para a produção de vinho e vinagre.

Há outras áreas de produção em crescimento, como a da Campanha, no Rio Grande do Sul; a de Curitiba, no Paraná; as de Caldas e Pirapora, em Minas Gerais; e a do Vale do Açu, no Rio Grande do Norte. Além das duas regiões já consagradas da viticultura tropical (Vale do São Franciso e noroeste do Estado de São Paulo), estão surgindo novos pólos com perspectivas de expansão tanto no Nordeste como no Centro-oeste do País.

O Chile exporta anualmente cerca de 60 milhões de caixas de $5 \mathrm{~kg}$, com faturamento aproximado de US $\$ 1$ bilhão; sendo 40 milhões de caixas deste total destinadas aos Estados Unidos (FNP, 1998). 
O Brasil produz 958.050 ton de uvas, em 58214 ha cultivados. Exporta 4.914 ton (US\$ 5 milhões) e importa 24.615 ton (US\$ 28,5 milhões), sendo o Chile o seu maior exportador com 10.608 ton, num total de US $\$ 12,6$ milhões (FNP, 1999).

As exportações brasileiras de uvas de mesa para Europa vêm crescendo nos últimos anos (1,1 milhão de caixas exportadas), entretanto, o mercado externo, especialmente o Americano (com 1,34 milhões de caixas), apresenta maior demanda por uvas apirênicas. Produtores do Vale do São Francisco têm restringido a expansão da área cultivada de uvas com sementes, pois, mercados que antes eram grandes consumidores, a exemplo do Inglês, terem também demonstrado igual tendência ao consumo de uvas apirênicas (FNP, 1998).

Alguns produtores tentaram em vão o cultivo de algumas uvas apirênicas, amplamente comercializadas no mercado externo, como a 'Thompson seedless' e 'Flame seedless', porém sem atingirem produções satisfatórias. Entre as possíveis causas do insucesso podem ser citadas a não adaptação dessas cultivares às condições climáticas regionais e ao uso inadequado de práticas de manejo, surgindo por parte dos produtores à necessidade de cultivares portadoras dessas características e adaptadas ao clima tropical da região. 


\subsection{Aspectos hormonais do florescimento e sobre a qualidade de bagas}

Hormônios vegetais são substâncias quimicas orgânicas naturais que regulam o crescimento e desenvolvimento, pelas modificações ocasionadas nos processos morfológicos e fisiológicos das plantas.

Reguladores vegetais são substâncias produzidas sinteticamente ou através de processos de fermentação, que quando aplicados exogenamente possuem atividades fisiológicas similares aos dos hormônios vegetais conhecidos, entre os quais, as auxinas, giberelinas, retardadores de crescimento e citocininas.

Auxinas são produzidas principalmente nas regiões apicais meristemáticas do caule e raizes, em folhas jovens, frutos e sementes, e possuem atividades na alongação celular (Cleland, 1987), atuam no foto e geotropismo; inibe brotações laterais de gemas em favor da dominância apical; promovem a iniciação e a alongação radicular; estão associadas ao crescimento de frutos, pela sua correlação com o desenvolvimento das sementes e o tamanho e a forma final do fruto (Crane, 1949); promovem a formação de frutos paternocárpicos; evitam a queda de folhas e frutos; e em altas concentrações podem atuar como herbicidas.

Giberelinas são encontradas principalmente nos tecidos em desenvolvimento de meristemas apicais, embriões e sementes em germinação. Promovem a alongação estimulando a divisão celular e o alongamento de plantas intactas; revertem o nanismo de plantas caracterizadas pelo encurtamento dos entrenós; induzem lançamento e florescimento de plantas com crescimento em roseta, sob condições não indutivas, que requerem $D L$ e vernalização para florescerem; produzem enzimas hidrolíticas como a $\alpha$-amilase na camada de aleurona, convertendo o amido do endosperma (reservas armazenadas) em açucares mais solúveis em água; promovem a plasticidade da parede celular e podem induzir o processo de germinação em sementes que normalmente requerem condição de frio para germinarem. 
Os retardadores de crescimento químicos podem ser classificados em dois grupos: os inibidores subapicais e os inibidores de crescimento geral. Os inibidores subapicais reduzem o alongamento dos internódios, sem interromper o crescimento do meristema apical e têm sido utilizados para duas finalidades básicas: retardar o crescimento, por inibir a expansão e a divisão celular, e para atrasar a brotação (Pires, 1998).

Neste grupo, os produtos mais utilizados (nome comum/comercial) são: Daminozide (SADH/Alar); Chlormequat (CCC/Cycocel); CBBP (Phosfon/Phosfon-D); Ancymidol (EL-531/A-Rest); Paclobutrazol (PP33/Cultar); Uniconazole/S-3307 e Flurprimido/EL-500. O grupo dos Inibidores de crescimento geral interrompe a atividade do meristema apical ou mata as brotações terminais, e pertencem a este grupo a Hidrazina Maleica (HD/Royal Slo-Gro); Chlorflurenols/Atrinal e o Fluoridamine/Sustar (Kozlowski et al., 1990).

Os inibidores subapicais agem freqüentemente no bloqueio da síntese de giberelinas, contrastando com o grupo de inibidores geral, que aparentemente não agem diretamente com nenhum dos hormônios de crescimento, e sim devem estar envolvidos no processo de divisão celular (Kozlowski et al., 1990).

O chlormequat, também denominado cycocel, cloreto de clorocolina ou CCC, um inibidor da expansão e da divisão celular da região subapical de crescimento, retarda o crescimento da planta atrasando a brotação, devido atuar no bloqueio da biossíntese de giberelinas (Kozlowski et al., 1990; Pires, 1998); e possui ação sinérgica na biossintese de citocininas realizada pelo sistema radicular da videira (Srinivasan \& Mullins, 1980).

Srinivasạn \& Mullins (1976) citam que a formação de inflorescências em várias cultivares de uva é acompanhada pela presença do anlagen (uma protuberância meristemática originada no ápice das gemas latentes); o anlagen pode se diferenciar em primórdios de inflorescências, ramos e/ou gavinhas; e, depois, o desenvolvimento dos respectivos primórdios; verificando-se os dois primeiros estádios nos periodos da estação corrente, e a formação completa das flores, com a brotação das gemas. 
De acordo com Snirivasan \& Mullins (1980), as giberelinas estão envolvidas na formação dos anlagens, contudo, se atuarem em uma fase posterior de desenvolvimento são prejudiciais para a formação das inflorescências, diferenciando-os em outros órgãos.

Durante o ciclo da videira, balanços de giberelinas e citocininas tendem a aumentar em direção das citocininas, poder-se-ia otimizar os gradientes de citocininas com produtos que inibam a ação das giberelinas (Kozlowski et al., 1990) e favorecer, desta forma, o florescimento.

Dados da PANS (1973), de ensaios realizados em vários países, sobre os efeitos da aplicação do CCC em plantas frutíferas lenhosas, relatam: para Pessegueiro: diminui o crescimento vegetativo, aumenta a diferenciação floral, concede maior resistência ao frio e aumenta a produção e a qualidade dos frutos, a $4000 \mathrm{mg} \cdot \mathrm{L}^{-1}$, aplicados em três intervalos mensais; Damasqueiro: aumenta o pegamento dos frutos a $600 \mathrm{mg} . \mathrm{L}^{-1}$; Castanheira: aumenta em $100 \%$ a produção de amêndoas, por reduzir a queda de botões florais e o pegamento de frutos, a $1000 \mathrm{mg} \cdot \mathrm{L}^{-1}$, aplicados uma semana antes do florescimento; Ameixeira: aumenta a produção a $500 \mathrm{mg} \cdot \mathrm{L}^{-1}$, aplicados no florescimento e, depois, no estádio de queda das pétalas, e em Mangueira: aumenta o florescimento quando são aplicados $1000 \mathrm{mg} \cdot \mathrm{L}^{-1}$ três vezes, em intervalos de 14 dias cada.

Especificamente para Videira, é citado que: a) $1600 \mathrm{mg} \cdot \mathrm{L}^{-1}$ aplicados 1-3 semanas antes do florescimento reduz a queda de botões florais, aumenta a produção e reduz de 10-15 \% o comprimento de sarmentos; b) 200$300 \mathrm{mg} \cdot \mathrm{L}^{-1}$ reduz a formação de uva-pedra, bem como o comprimento das varas, provocando, contudo, diminuição do teor de sólidos solúveis totais; c) 500-1000 $\mathrm{mg} . \mathrm{L}^{-1}$ aplicados durante o florescimento aumentam o número e o peso individual de bagas, resultando num maior peso de cacho; d) $1200 \mathrm{mg} \cdot \mathrm{L}^{-1}$ aplicados antes do florescimento aumenta a produção, os cachos são mais compactos e diminui a formação de bagas pequenas.

Coombe (1970), buscando determinar os mecanismos dos efeitos do $\mathrm{CCC}$, concluiu que o aumento do pegamento de frutos em Vitis vinifera está 
relacionado com a inibição do crescimento dos brotos, sendo os nutrientes orgânicos desviados para o desenvolvimento de ovários, tanto nas variedades com sementes como nas apirênicas.

Alguns retardadores de crescimento podem vir a reduzir a taxa fotossintética, como o Daminozide (SADH), que induziu menor tamanho dos frutos de macieira; contudo, pela combinação de $\mathrm{GA}_{4-7}$ com Benzyladenina, aplicados antes da antese, pode-se reduzir seus efeitos negativos (Kozlowski et al., 1990).

As citocininas são encontradas principalmente em regiões apicais de raízes (Kende \& Sitton, 1967) e frutos. Elas promovem a divisão e o alongamento celular, e sob gradientes ótimos de auxinas promovem a diferenciação celular em plantas intactas ou não; conferem a germinação de sementes fotoblásticas positivas, inclusive no escuro, como as de alface; o desenvolvimento de gemas e brotações, devido à quebra da dominância apical, ao inibir a AIA oxidase encontrada nas gemas laterais e alocar vitaminas, minerais e outras substâncias de crescimento para as gemas; é responsável pela manutenção da atividade metabólica celular ao retardar a senescência e por atuar na integridade da membrana do tonoplasto (Thimann, 1987).

Citocininas estão envolvidas com o controle de vários aspectos da reprodução da videira, e poderiam estar associadas com a partição de assimilados e na regulação dos metabólicos, segundo Mullins et al. (1992).

O potencial de dediferenciação de gavinhas e sua diferenciação para inflorescências pelo uso de citocininas foram demonstrados por Srinivasan \& Mullins (1978) quando aplicaram BA ou 6-(benzylamino)-9-(2tetrahydropyranyl)-9H-purine (PBA) em ápices de gavinhas cultivadas em meio líquido sob agitação, observando-se desenvolvimentos normais de cálice, corola, estames e pistilos, porém não foram observadas as etapas de micro e macrosporogênese.

As bagas de uvas apirênicas tendem a ter tamanhos reduzidos pela ausência das sementes e de fitormônios que as façam crescer, sendo a 
aplicação de fitorreguladores de crescimento indispensável como parte de um manejo direcionado à melhoria da qualidade dos cachos.

O forchlorfenuron (CPPU) tem ação citocinínica, favorece a divisão e a expansão celular, atrasa o amadurecimento das bagas, tornando-as maiores (Reynolds et al., 1992, Pires, 1998), mas não é registrado no Ministério da Agricultura e do Abastecimento para utilização em videira (Miele et al., 1998).

$\mathrm{O}$ ácido giberélico $\left(\mathrm{GA}_{3}\right)$ tem sido muito utilizado para aumentar o tamanho das bagas. Atua na produção da $\alpha$-amilase aumentando os teores de açucares e conseqüentemente na pressão osmótica do suco celular, acarretando um maior fluxo de água para o interior da célula, propiciando a sua elongação.

Sarig et al. (1998) avaliaram os efeitos do CPPU e do $\mathrm{GA}_{3}$ sobre as bagas das cultivares Thompson seedless e Zeiny, e concluíram que os efeitos anatômicos causados pelo CPPU foram devido a um aumento na divisão celular, resultando células menores e em alta densidade, causando o engrossamento da casca das bagas; em contrapartida, o $\mathrm{GA}_{3}$ provoca um aumento significativo no tamanho das células, especificamente daquelas localizadas na hipoderme.

Tomer $(1990,1992,1994)$ em estudos com as cultivares Cardinal, Perlette e Beauty seedless, correlacionou a produção com o número de varas deixadas por planta (12, 16, 20 e 24 varas/planta). Plantas com 24 varas, podadas com 5 gemas (120gemas/planta) obtiveram as maiores produções, ou seja, 13,6, 16,8 e 11,8 kg/planta, respectivamente para as cultivares Perlette, Beauty seedless e Cardinal. 


\section{CRESCIMENTO DE BAGAS DE UVAS APIRÊNICAS (Vitis vinifera L.) TRATADAS COM CPPU E GA}

\section{Resumo}

As cultivares de uvas apirênicas, em via de regra, possuem tamanhos de bagas reduzidas, necessitando de ajustes no manejo para a melhoria da qualidade dos cachos, sendo a aplicação de reguladores de crescimento um dos tratamentos mais eficazes. Objetivou-se com o presente trabalho avaliar os efeitos do Forchlorfenuron (CPPU: 0 e $10 \mathrm{mg} \cdot \mathrm{L}^{-1}$ ) combinado ao Ácido giberélico $\left(\mathrm{GA}_{3}:\right.$ 0, 25, 50, 75 e $\left.100 \mathrm{mg} \cdot \mathrm{L}^{-1}\right)$ durante o primeiro ciclo de produção das cultivares Vitis vinifera (L.) Centennial seedless, Flame seedless e Thompson seedleess. As características avaliadas de crescimento de bagas foram o comprimento, largura e peso. A aplicação de $100 \mathrm{mg} \cdot \mathrm{L}^{-1} \mathrm{de} G \mathrm{G}_{3}$ foi a mais responsiva para a 'Centennial seedless'; sendo para a 'Flame seedless' $\mathrm{e}$ 'Thompson seedless' esta mesma concentração de $\mathrm{GA}_{3}$ adicionada a $10 \mathrm{mg} \cdot \mathrm{L}^{-1}$ de CPPU. Houve redução nos teores de sólidos solúveis totais do mosto das cultivares pelo efeito da aplicação com os fitorreguladores, retardando a época da colheita.

Palavras-chave: uva para mesa, forchlorfenuron, ácido giberélico, citocininas, fisiologia da produção. 


\section{INCREASE OF THE BERRY APIRENIC (Vitis vinifera L.) ' TREATY WITH CPPU AND GA 3}

\section{Summary}

The seedless grapes, always have decrease in berry size, requiring managements to increase cluster quality. The spray with growth regulators is the treatment preferentially to enlarge berry size. The objective of this work was to determine the effects of Forchlorfenuron (CPPU: 0 e $10 \mathrm{mg} \cdot \mathrm{L}^{-1}$ ) associated with Giberelic acid $\left(\mathrm{GA}_{3}: 0,25,50,75\right.$ e $\left.100 \mathrm{mg} \cdot \mathrm{L}^{-1}\right)$ interaction about increase in berry size on first harvest cycle of the seedless Centennial, Flame and Thompson table grapes. Higher berry length, breadth and weight were in average obtained at $100 \mathrm{mg} \cdot \mathrm{L}^{-1} \mathrm{GA}_{3}$ for 'Centennial seedless'; and $100 \mathrm{mg} \cdot \mathrm{L}^{-1} \mathrm{GA}_{3}$ in associated with $10 \mathrm{mg} . \mathrm{L}^{-1} \mathrm{CPPU}$ for the cultivars Flame seedless and Thompson seedless, and were delayed fruits maturation in terms of soluble solids content of all table grape cultivars.

Key words: table grapes, forchlorfenuron, gibberellic acid, cytokines, and physiology of production

\subsection{Introdução}

A produção de uvas apirênicas para mesa no Brasil carece de cultivares bem adaptadas e produtivas. A criação de cultivares com qualidades de cachos exigidas pelos mercados demanda tempo, tornando-se a introdução de cultivares a via mais rápida para a solução deste problema. No entanto, a grande maioria das cultivares já introduzida tem apresentado baixa produção e qualidade de cachos, necessitando-se de ajustes no manejo (Camargo, 1998). 
A 'Centennial seedless`, obtido por Olmo \& Oyama na Califórnia (EUA), trata-se de uma cultivar bem difundida na Região Noroeste Paulista; produz em média um cacho por ramo, são grandes, cheios, porém não compactos, e as bagas são alongadas e afiladas na ponta, esverdeadas, sabor neutro, crocante e levemente aromático; porém tem problemas de degrana e quando amadurecem sob intenso calor as bagas apresentam manchas na película.

A 'Flame seedless', obtido pelo Departamento de Agricultura dos Estados Unidos, em Fresno, Califórnia, é tido como promissor para a região do Vale do São Francisco (BA/PE), chegando a produzir em torno de 18 ton/ha; seus cachos são médios, cônicos, moderadamente soltos, e as bagas são pequenas, arredondadas, avermelhadas, textura firme, sabor neutro e doce.

A 'Thompson seedless', quando cultivado em região de intenso calor torna-se produtivo, sendo a cultivar de menor adaptação aos nossos sistemas tropicais de cultivo, quando comparada às duas últimas citadas; tem cachos grandes, alados, cilíndrico-alongados e compactos, e as bagas são esverdeadas ou levemente douradas quando maduras, textura firme, sabor neutro e doce, (Camargo et al., 1997; Camargo, 1998; Pommer, 1998; Terra et al., 1998).

As bagas de uvas apirênicas tendem a ter tamanhos reduzidos pela ausência das sementes e de fitormônios, sendo a aplicação de fitorreguladores de crescimento indispensável como parte do manejo para a melhoria da qualidade dos cachos.

$\mathrm{O}$ ácido giberélico $\left(\mathrm{GA}_{3}\right)$ aumenta o tamanho das bagas. Atua na produção da $\alpha$-amilase aumentando os teores de açucares e conseqüentemente na pressão osmótica do suco celular, acarretando um maior influxo de água para o interior da célula, propiciando a sua elongação. O forchlorfenuron (CPPU) tem ação citocinínica, favorece a divisão e a expansão celular e atrasa o amadurecimento das bagas, tornando-as maiores (Reynolds et al., 1992, Pires, 1998). 
Sarig et al. (1998) avaliaram os efeitos do CPPU e do $\mathrm{GA}_{3}$ sobre as bagas das cultivares Thompson seedless e Zeiny, e concluíram que os efeitos anatômicos causados pelo CPPU foram devido a um aumento na divisão celular, resultando células menores e em alta densidade, seguida do engrossamento da casca das bagas; em contrapartida, o $\mathrm{GA}_{3}$ provoca um aumento significativo no tamanho das células, especificamente daquelas localizadas na hipoderme.

O thidiazuron (TDZ) é uma outra phenylurea que também tem sido utilizado com sucesso para o crescimento das bagas (Reynolds et al., 1992; Czermainski \& Camargo, 1998), ressaltando-se, portanto, os benefícios não apenas das giberelinas como também das citocininas (Weaver et al., 1966) para o crescimento das bagas da videira.

$\mathrm{O}$ uso do $\mathrm{GA}_{3}$ isolado ou combinado com o CPPU tem favorecido a melhoria da qualidade das bagas em várias cultivares apirênicas ou não.

Para a cultivar Itália recomenda-se para as condições do Noroeste Paulista de 20 a $40 \mathrm{mg} \cdot \mathrm{L}^{-1}$, aproximadamente 30 dias após o pleno florescimento (Terra et al., 1998); Muñoz (1987) e Retamales et. al. (1995) obtiveram no Chile aumentos no tamanho das bagas da 'Thompson seedless' com a aplicação de $40 \mathrm{mg} \cdot \mathrm{L}^{-1}$ de $\mathrm{GA}_{3}$, e, de acordo com o fabricante BASF Agro, citado por Pires (1998), recomenda-se a aplicação de $10 \mathrm{mg} \cdot \mathrm{L}^{-1}$ as cultivares Red Globe e Thompson seedless, contudo, é um produto não registrado no Ministério da Agricultura e do Abastecimento para utilização em videira (Miele et al., 1998; Leão et al., 1999).

Trabalhos conduzidos com 'Perlette' e 'Flame seedless' (Diaz \& Maldonado, 1992), 'Sovereign Coronation`e 'Sommerland' (Reynolds et al., 1992) e 'Perlette' (Leão et al., 1999) observaram-se efeitos maximizadores pelo uso conjunto do CPPU com o $\mathrm{GA}_{3}$.

Objetivou-se com o presente trabalho estudar o efeito do CPPU e do $\mathrm{GA}_{3}$ sobre o crescimento de bagas das cultivares $V$. vinifera (L.) Flame seedless, Centennial seedless e Thompson seedless, durante as suas primeiras épocas de produção. 


\subsection{Material e Métodos}

O experimento foi executado em vinhedo comercial localizado no municipio de Porto Feliz, SP, na propriedade do senhor Antonio Portronieri, associado da AVIPORTO (Associação dos Viticultores de Porto Feliz)- situado a $23^{\circ} 12^{\prime} \mathrm{S}, 47^{\circ} 31^{\prime} \mathrm{W}$ e altitude $540 \mathrm{~m}$.

As cultivares Centennial seedless, Flame seedless e Thompson seedless foram enxertadas em agosto de 1999 sobre 9 plantas do IAC-572 'Jales', plantadas no espaçamento $3,0 \times 3,60 \mathrm{~m}$, e conduzidas em sistema de latada.

O solo, do tipo podzólico, demonstrou com a análise química

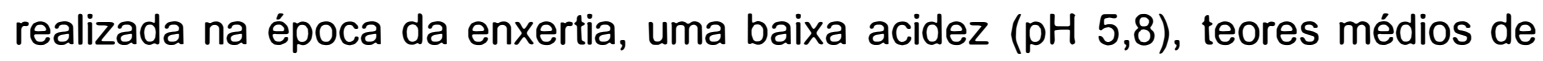
matéria orgânica e saturação por bases igual a 86 \%; indicando condições perfeitas de acidez e fertilidade (Lopes \& Guidolin, 1992).

Observou-se que, de acordo com as recomendações adotadas para adubação- formação após a enxertia das cultivares Centennial seedless e Ruiva (Terra et al., 1998)-, os solos da área experimental encontravam-se adequados para o cultivo da videira.

Partindo do pressuposto que um desequilibrio nutricional, principalmente no que se refere ao nitrogênio disponivel, poderia acarretar um alto desenvolvimento vegetativo e, devido as plantas de Flame seedless e Thompson, por si, já serem muito vigorosas, e também, para que adubações químicas ou orgânicas não interferissem sobre os possiveis efeitos dos tratamentos com fitorreguladores a serem aplicados, não foram tomadas quaisquer medidas em relação ao estado nutricional das plantas durante o transcorrer dos experimentos.

O regime pluviométrico de Porto Feliz foi obtido através do SIGRH Sistema Integrado de Gerenciamento de Recursos Hídricos do Estado de São Paulo. A média anual dos últimos cinco anos foi de 1310,1 mm, com médias mensais de 109,2 $\mathrm{mm}$ e desvio padrão de $16,71 \mathrm{~mm}$, sendo que $76,16 \%$ das chuvas deste período ocorreram nos meses de outubro a março. 
Após as podas, aplicou-se nas gemas, na forma de pincelamento, cianamida hidrogenada (Dormex-5\%) para quebra de dormência e uniformidade da brotação.

A fertilidade de gemas foi tomada em toda a extensão da planta, pelo número de brotos e inflorescências na coroa e varas em 25 de setembro de 2000.

Com 15 dias após o pleno florescimento, os cachos foram pulverizados com forchlorfenuron (CPPU: 0 e $10 \mathrm{mg} \cdot \mathrm{L}^{-1}$ ) em associação com o ácido giberélico $\left(\mathrm{GA}_{3}: 0,25,50,75\right.$ e $\left.100 \mathrm{mg} \cdot \mathrm{L}^{-1}\right)$, em todas as combinações possiveis. O experimento foi conduzido em delineamento de blocos casualizados, em esquema fatorial $2 \times 5$, com quatro repetições, tendo-se uma planta por parcela.

As avaliações foram realizadas através do comprimento, largura e peso médio de 100 bagas, retiradas de um total de cinco cachos amostrados por planta. Para a análise do teor de sólidos solúveis totais ( ${ }^{\circ} \mathrm{Brix}$ ) foram coletadas de cada cacho uma baga da região apical, duas da central, e uma da basal, compondo-se, portanto, amostras de 20 bagas para cada tratamento. As medições de todos os tratamentos foram realizadas em um mesmo momento, a partir da constatação do mínimo recomendável de $14{ }^{\circ}$ Brix para a colheita (Almeida, 2001), verificado no tratamento controle.

Para fins de análise estatística, as variáveis comprimento, largura e peso médio das bagas das três cultivares foram transformadas segundo raiz quadrada de $x+0,5$ e interpretadas por meio de análise de variância e regressão, baseando-se para a escolha dos modelos a significância dos coeficientes de regressão, utilizando-se o teste "t" $(\alpha<0,05)$ e o coeficiente de determinação $\left(R^{2}>0,70\right)$. 


\subsection{Resultados e Discussão}

O CPPU não teve efeito significativo sobre a largura e o peso de baga da 'Centennial seedless', e a combinação com $\mathrm{GA}_{3}$ também não foi significativa para o peso de baga da 'Thompson seedless'; contudo, em termos gerais, os efeitos dos dois fatores foram altamente significativos $(\alpha<0,01)$ para as características comprimento, largura e peso de baga das cultivares Centennial seedless, Flame seedless e Thompson seedless (Tabela 1).

Tabela 1. Análise de variância das variáveis comprimento, largura e peso de bagas das cultivares Centennial seedless, Flames seedless e Thompson seedless. ESALQ-USP, Piracicaba, 2002.

\begin{tabular}{|c|c|c|c|c|c|c|c|c|c|c|}
\hline \multicolumn{2}{|l|}{ Fonte } & \multicolumn{9}{|c|}{ QUADRADOS MÉDIOS } \\
\hline $\mathrm{De}$ & GL & \multicolumn{3}{|c|}{ Comprimento de } & \multicolumn{3}{|c|}{ Largura de } & \multicolumn{3}{|c|}{ Peso de } \\
\hline \multirow[t]{2}{*}{ Variação } & & \multicolumn{3}{|c|}{ Baga } & \multicolumn{3}{|c|}{ Baga } & \multicolumn{3}{|c|}{ Baga } \\
\hline & & Cv.1 & Cv.2 & Cv.3 & Cv.1 & Cv.2 & Cv.3 & Cv.1 & Cv.2 & Cv.3 \\
\hline \multirow[t]{2}{*}{ CPPU } & 1 & $0,0764^{\star}$ & $0,3850^{\star}$ & $0,6878^{\star}$ & 0,0099 & $0,3653^{\star}$ & $0,7282^{\star}$ & 0,0571 & $8,3018^{\star}$ & $9,4702^{*}$ \\
\hline & & * & * & * & ns & $\star$ & $\star$ & ns & * & * \\
\hline \multirow[t]{2}{*}{$\mathrm{GA}_{3}$} & 4 & $0,2397^{\star}$ & $0,0717^{\star}$ & $0,0594^{\star}$ & $0,0297^{\star}$ & $0,0479^{\star}$ & $0,0232^{*}$ & $8,1167^{\star}$ & $2,0107^{\star}$ & 0,6122 \\
\hline & & * & * & * & * & * & * & * & * & ns \\
\hline \multirow[t]{2}{*}{$\mathrm{CPPU}^{*} \mathrm{GA}_{3}$} & 4 & $0,2494^{*}$ & $0,0488^{*}$ & $0,0162^{*}$ & $0,0861^{*}$ & $0,0278^{\star}$ & $0,0077^{\star}$ & $4,7718^{\star}$ & $0,5128^{\star}$ & 0,5737 \\
\hline & & * & * & * & * & * & * & * & * & ns \\
\hline \multirow[t]{2}{*}{ Resíduo } & 30 & 0,0090 & 0,0058 & 0,0033 & 0,0076 & 0,0047 & 0,0021 & 0,4612 & 0,0568 & 0,4528 \\
\hline & $\operatorname{CV}(\%)=$ & 3,19 & 4,98 & 3,15 & 4,45 & 4,31 & 2,86 & 9,75 & 8,34 & 24,94 \\
\hline
\end{tabular}

Cv.1: 'Centennial seedless`; Cv.2: 'Flame seedless`; Cv.3: 'Thompson seedless'; ${ }^{\star} \mathrm{F}$ : significativo ( $\alpha<$ 0,01); ns: não significativo.

A cultivar Centennial seedless possui naturalmente bagas superiores às da Flame seedless e Thompson seedless, em comprimento, largura e peso, que podem ser verificados nos tratamentos com a ausência dos produtos (Figura 1, 2 e 3). 
$Y^{\prime}$ Centennial sds' CPPU $0=2,827357-0,0005556 x+0,00004649 x^{2}$

$Y^{\prime}$ Centennial seedless' CPPU $10 \mathrm{mg} \cdot \mathrm{L}^{-1}=2,889057+0,0101186 \mathrm{x}-0,00014589 \mathrm{x}^{2} \quad \mathrm{R}^{2}=0,74$

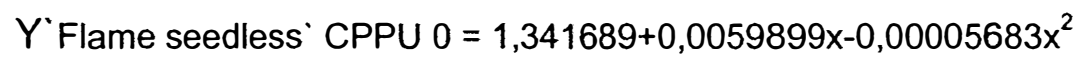

$Y^{\prime}$ 'Flame seedless' CPPU $10 \mathrm{mg} \cdot \mathrm{L}^{-1}$ (média geral) $=1,62 \mathrm{~cm}$

$Y^{\prime}$ Thompson seedless' CPPU $0=1,590429+0,0052137 x-0,00004526 x^{2}$

$Y^{`}$ 'Thompson seedless' CPPU $10 \mathrm{mg} \cdot \mathrm{L}^{-1}$ (média geral) $=1,94 \mathrm{~cm}$

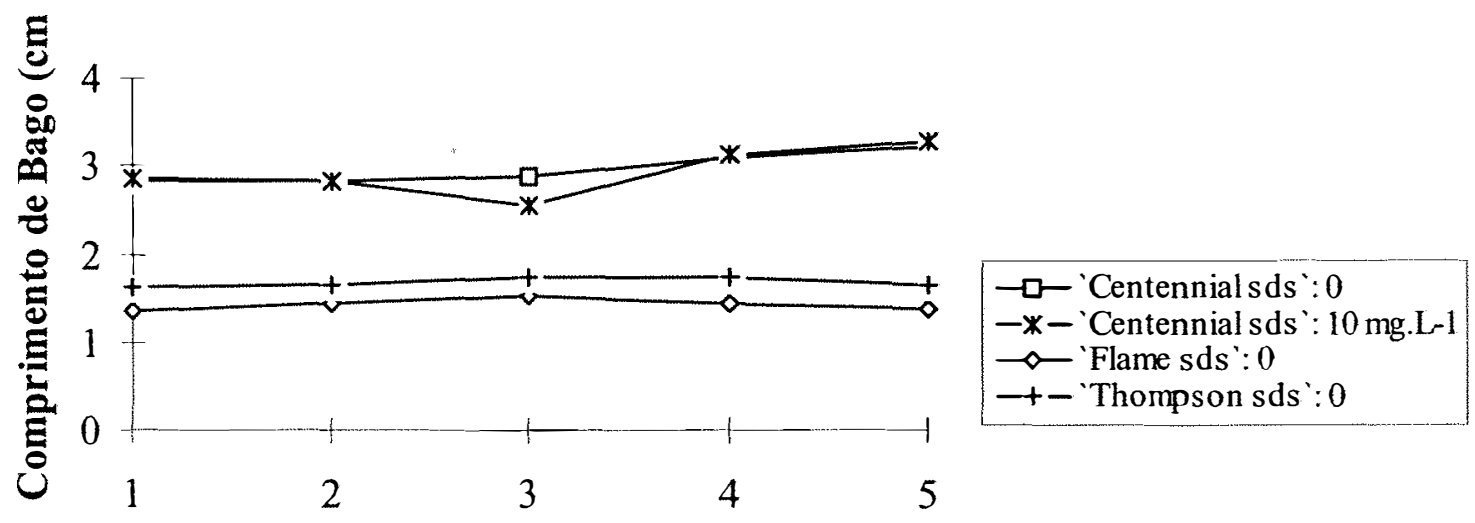

\section{Ácido Giberélico (mg.L-1)}

Figura 1 - Efeito do CPPU e $\mathrm{GA}_{3}(1 ; 2 ; 3 ; 4$ e 5, respectivamente 0; 25; $50 ; 75$ e $100 \mathrm{mg} \cdot \mathrm{L}^{-1}$ de $\mathrm{GA}_{3}$ ) sobre o comprimento de bagas das cultivares Centennial seedless, Flame seedless e Thompson seedless. ESALQ-USP, Piracicaba, 2002.

Observa-se, também, que a concentração de $10 \mathrm{mg} \cdot \mathrm{L}^{-1}$ de CPPU interagiu positivamente com os níveis utilizados de $\mathrm{GA}_{3}$ e promoveu ganhos maiores do que com $0 \mathrm{GA}_{3}$ aplicado isoladamente para a característica comprimento de baga da cultivar 'Centennial seedless' (Figura 1); para a largura de baga em 'Flame seedless' e 'Thompson seedless (Figura 2); e para o peso de baga em 'Flame seedless` e 'Centennial seedless` (Figura 3). 
$Y^{\prime}$ Centennial seedless' CPPU $0=1,886425+0,0013780 x$ $\mathrm{R}^{2}=0,80$

$Y^{\prime}$ Centennial seedless' CPPU $10 \mathrm{mg} \cdot \mathrm{L}^{-1}$ (média geral) $=1,97 \mathrm{~cm}$

$Y^{\prime}$ Flame seedless' CPPU $0=1,443019+0,0052681 x-0,00005478 x^{2}$ $\mathrm{R}^{2}=0,77$

Y'Flame seedless' CPPU $10 \mathrm{mg} \cdot \mathrm{L}^{-1}=1,542754+0,0198869 \mathrm{x}-0,00049759 \mathrm{x}^{2}$ $\mathrm{R}^{2}=0,99$

$Y^{\prime}$ 'Thompson seedless' CPPU $0=1,367543+0,0042486 x-0,00003509 x^{2}$ $\mathrm{R}^{2}=0,94$ $Y^{`}$ Thompson seedless` CPPU $10 \mathrm{mg} \cdot \mathrm{L}^{-1}=1,631550+0,0017340 \mathrm{x}$ $\mathrm{R}^{2}=0,93$

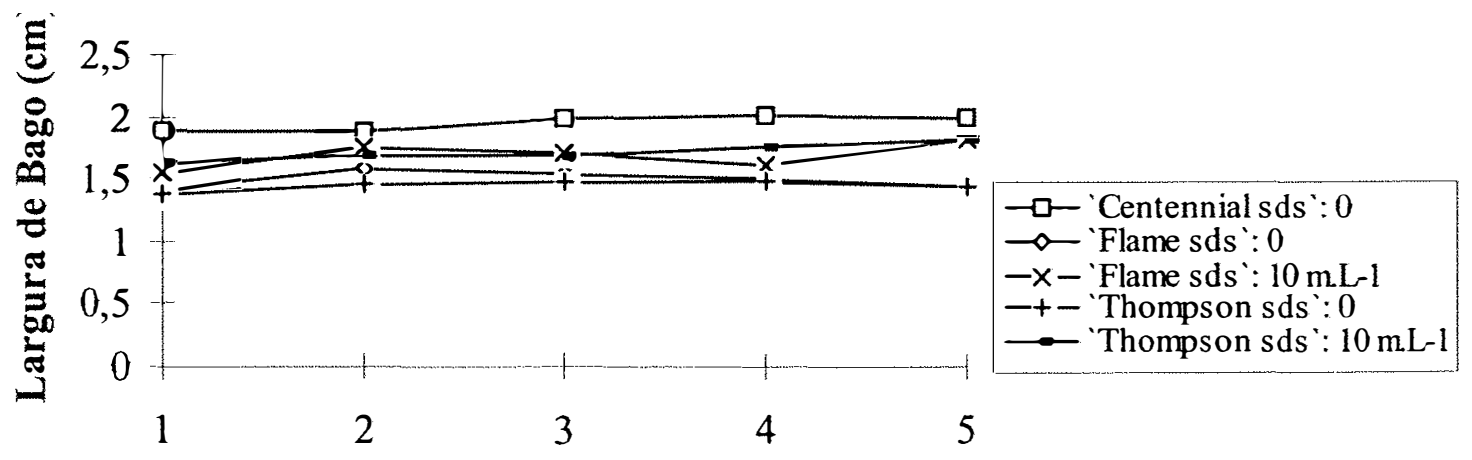

Ácido Giberélico (mg.L-1)

Figura 2 - Efeito do CPPU e $\mathrm{GA}_{3}(1 ; 2 ; 3 ; 4$ e 5, respectivamente $0 ; 25 ; 50 ; 75$ e $100 \mathrm{mg} \cdot \mathrm{L}^{-1}$ de $\mathrm{GA}_{3}$ ) sobre a largura de bagas das cultivares Centennial seedless, Flame seedless e Thompson seedless. ESALQ-USP, Piracicaba, 2002.

Resultados semelhantes foram observados por Lee et al. (1996) no aumento na massa dos frutos, cachos e diâmetro das bagas em 'Kyoho' por imersão em mistura de $\mathrm{GA}_{3}$ a $25 \mathrm{mg} \cdot \mathrm{L}^{-1}$ e citocinina a $10 \mathrm{mg} \cdot \mathrm{L}^{-1}$. Nickell (1985); Diaz \& Maldonado (1992); Reynolds et al. (1992); Sarig et al. (1998); e Leão et al. (1999) atribuem o melhor desempenho para a mistura como conseqüências do sinergismo do $\mathrm{GA}_{3}$ com a ação citocinínica do CPPU sobre o crescimento das bagas.

Quando aplicado isoladamente na 'Centennial seedless', o $\mathrm{GA}_{3}$ mostrou resultados semelhantes à mistura com CPPU, na concentração de 100 mg. $\mathrm{L}^{-1}$. Isto pode ser observado nas Figuras 1, 2 e 3, para as características comprimento, largura e peso de baga, atingindo respectivamente médias de 3,2 
$\mathrm{cm}, 2,0 \mathrm{~cm}$ e 8,4 g.. Evidencia-se assim que mesmo tendo a concentração de 10 mg. $\mathrm{L}^{-1}$ de CPPU interagido positivamente com o $\mathrm{GA}_{3}$, o CPPU torna-se dispensável para aumentar o crescimento e peso de bagas desta cultivar (Figura 4).

$Y^{\prime}$ Centennial seedless' CPPU $0=5,126357+0,0619714 x-0,00032571 x^{2}$ $R^{2}=0,84$

$Y^{\prime}{ }^{\prime}$ Centennial seedless' CPPU $10 \mathrm{mg}^{\circ} \mathrm{L}^{-1}=6,735715-0,0453972 \mathrm{x}-0,00065657 \mathrm{x}^{2}$ $R^{2}=0,86$

$Y^{\prime}{ }^{\prime}$ Flame seedless' CPPU $0=1,912996+0,0793290 x-0,00174351 x^{2}+0,000009795 x^{3}$ $R^{2}=0,97$

$Y^{\prime}$ 'Flame sds' CPPU $10 \mathrm{mg} \cdot \mathrm{L}^{-1}=2,591425+0,1217353 \mathrm{x}-0,00317374 \mathrm{x}^{2}+0,000020917 \mathrm{x}^{3} \quad \mathrm{R}^{2}=1,00$ $Y$ 'Thompson seedless' CPPU 0 (média geral) $=2,16 \mathrm{~g}$ $\mathrm{Y}^{`}$ Thompson seedless` CPPU $10 \mathrm{mg} \cdot \mathrm{L}^{-1}$ (média geral) $=3,35 \mathrm{~g}$

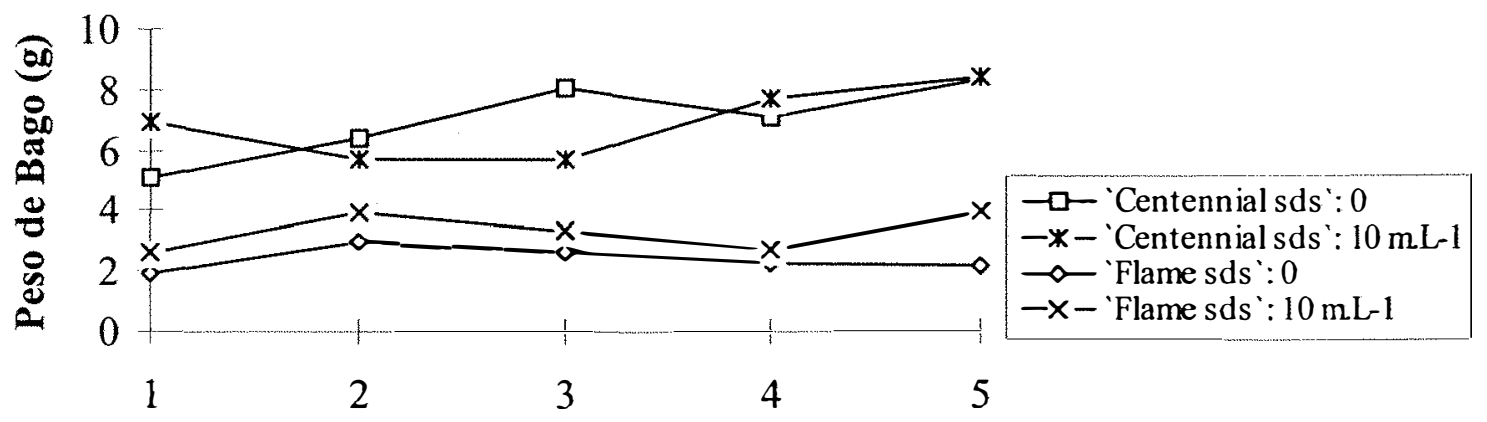

Ácido Giberélico (mg.L-1)

Figura 3 - Efeito do CPPU e $\mathrm{GA}_{3}(1 ; 2 ; 3 ; 4$ e 5, respectivamente 0; 25; $50 ; 75$ e $100 \mathrm{mg} \cdot \mathrm{L}^{-1}$ de $\mathrm{GA}_{3}$ ) sobre o peso de bagas das cultivares Centennial seedless, Flame seedless e Thompson seedless. ESALQ-USP, Piracicaba, 2002.

Esses resultados são diferentes aos de Pires (1998), onde o melhor tratamento foi obtido a $25 \mathrm{mg} \cdot \mathrm{L}^{-1}$ de $\mathrm{GA}_{3}$; entretanto, Reynolds et al. (1992) utilizaram com sucesso a concentração de $100 \mathrm{mg} \cdot \mathrm{L}^{-1}$ de $\mathrm{GA}_{3}$ para cachos da cultivar Sovereign Coronation. Assim, atenta-se que sob diferentes particularidades de cultivo, cultivares e climas devem ser levados em consideração para uma melhor eficiência dos fitorreguladores. 


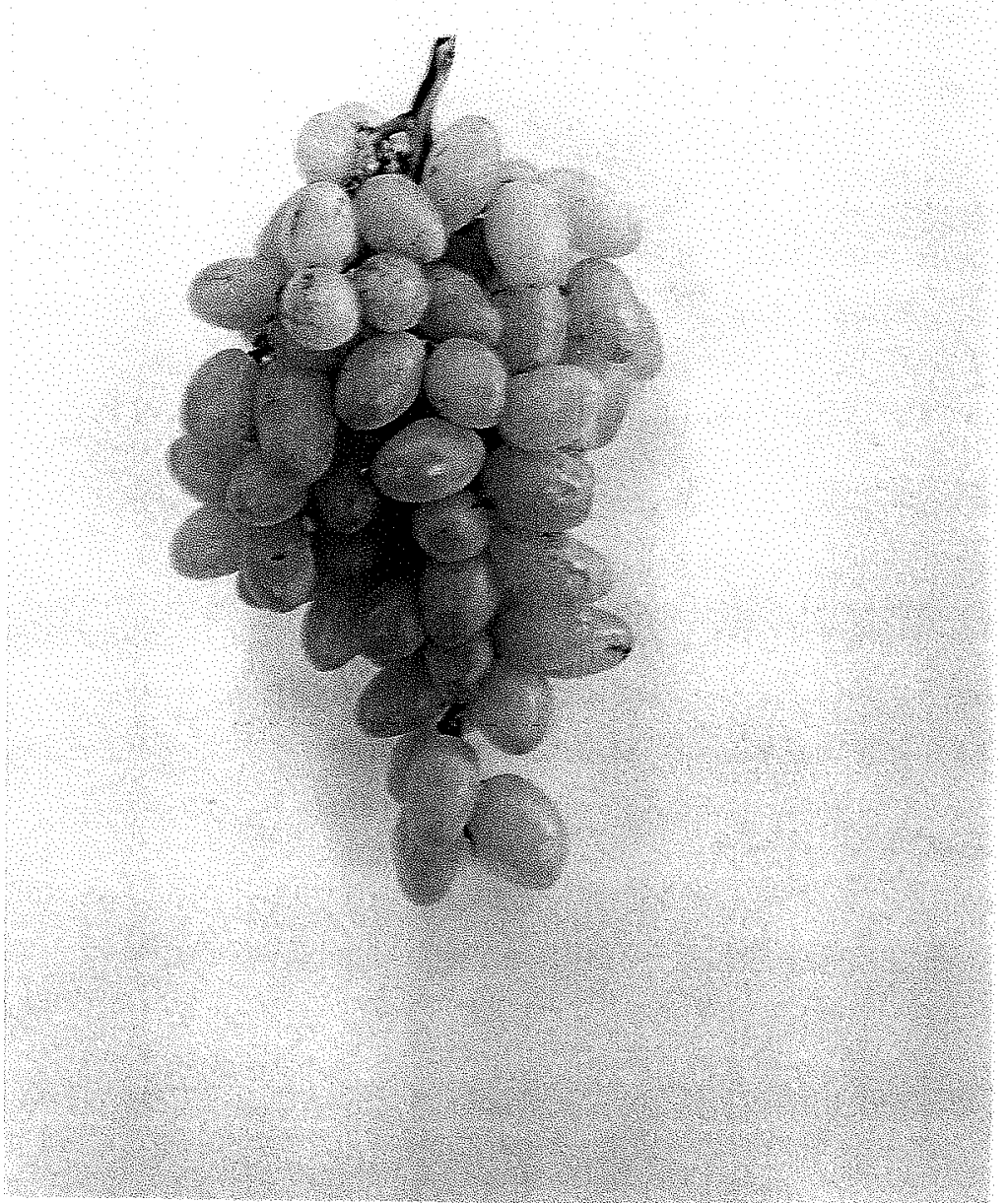

Figura 4 - Cachos da 'Centennial seedless', tratados com $100 \mathrm{mg}^{\mathrm{L}} \mathrm{L}^{-1}$ de $\mathrm{GA}_{3}$. ESALQ-USP, Piracicaba, 2002.

Para a 'Flame seedless', o comprimento máximo de baga $(1,5 \mathrm{~cm})$ foi conseguido com $52,7 \mathrm{mg} \cdot \mathrm{L}^{-1}$ de $\mathrm{GA}_{3}$. Para largura e peso da baga a associação de $10 \mathrm{mg} \cdot \mathrm{L}^{-1}$ de CPPU com $0 \mathrm{GA}_{3}$ sempre promoveu ganhos superiores aos efeitos isolados do $\mathrm{GA}_{3}$, sendo as concentrações de 25 e 100 mg. $\mathrm{L}^{-1}$ de $\mathrm{GA}_{3}$ aquelas que igualmente interagiram com o CPPU, maximizando a largura e o peso de baga, respectivamente a 1,8 cm e 3,9 g (Figura 5). 
Manteve-se uma tendência linear de aumentos na largura da baga da 'Thompson seedless' com o CPPU a $10 \mathrm{mg} \cdot \mathrm{LL}^{-1}$ para com todos os niveis de $\mathrm{GA}_{3}$, verificando-se $1,8 \mathrm{~cm}$ com a concentração de $100 \mathrm{mg} \cdot \mathrm{L}^{-1}$ de $\mathrm{GA}_{3}$ (Figura 6).

Já para a característica comprimento de baga, somente para a ausência do CPPU verificaram-se ajustes de dados a um modelo (R2>0,70), computando-se o comprimento $1,7 \mathrm{~cm}$ com $57,6 \mathrm{mg}^{-1} \mathrm{~L}^{-1}$ de $\mathrm{GA}_{3}$. Já para peso de baga, não foram observadas diferenças significativas com a aplicação de CPPU e $G_{3}$, o que também foi verificado por Joublan et al. (1995) com a cultivar Moscatel Rosada através do uso de $\mathrm{GA}_{3}\left(35 \mathrm{mg}^{\mathrm{L}} \mathrm{L}^{-1}\right)$ e $\operatorname{CPPU}\left(0,2\right.$, 4 e $\left.6 \mathrm{mg} . \mathrm{L}^{-1}\right)$; porém, Rematales et al. (1995) obtiveram aumentos significativos no peso de baga da 'Thompson seedless' com a combinação desses dois fitorreguladores.

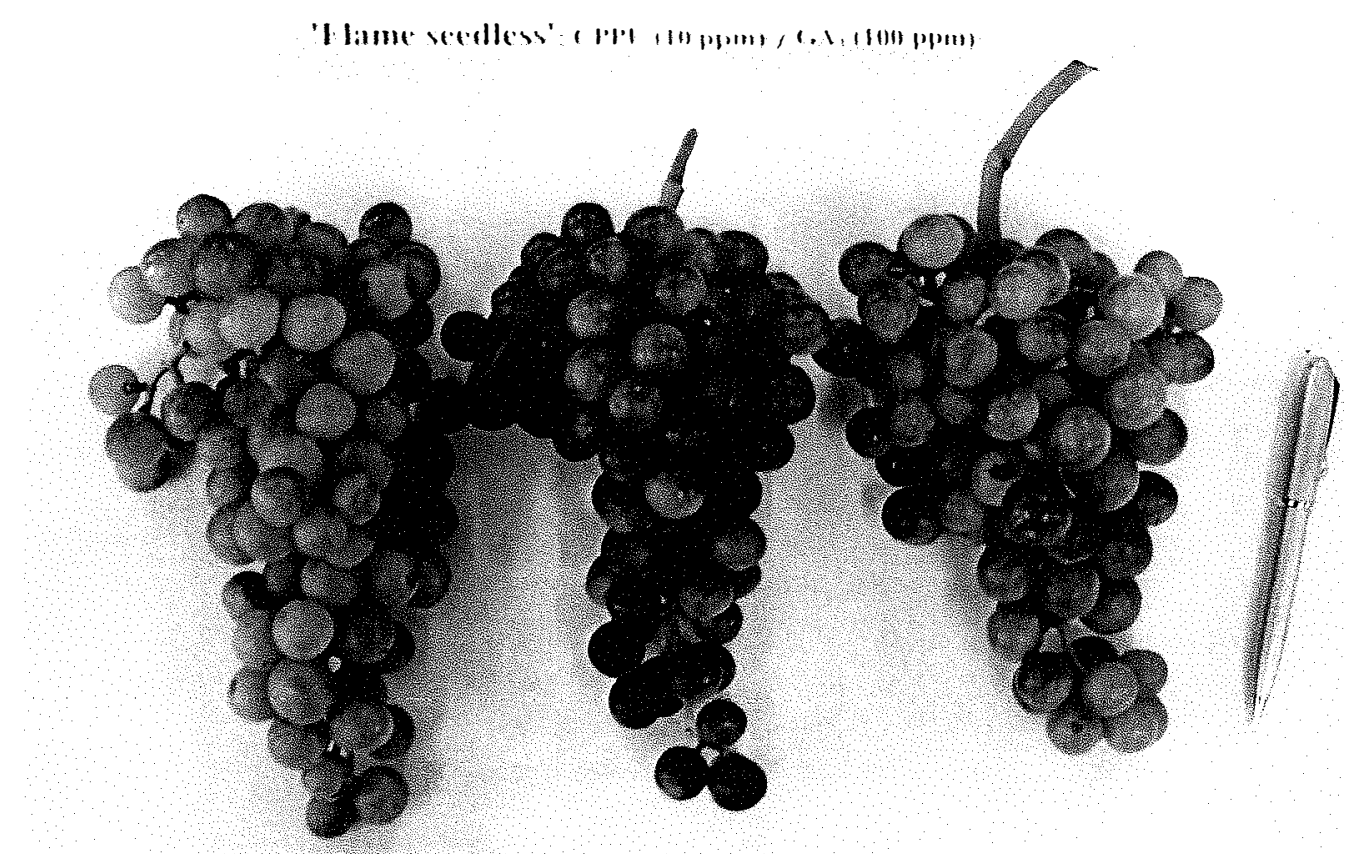

Figura 5 - Cachos da 'Flame seedless', tratados com $10 \mathrm{mg} \cdot \mathrm{L}^{-1}$ de CPPU e 100 mg.L-1 de GA ${ }^{-1}$. ESALQ-USP, Piracicaba, 2002. 
Portanto, conclui-se que os tratamentos com fitorreguladores foram efetivos para a melhoria da qualidade de baga das três cultivares; que de acordo com as Normas de classificação de uvas finas de mesa (V. vinifera L.) do "Programa brasileiro para a melhoria dos padrões comerciais e embalagens de hortifrutigranjeiros" (Almeida, 2001), em média, as bagas da 'Centennial seedless` situaram-se no calibre 21 (diâmetro de bagas) com $100 \mathrm{mg} \cdot \mathrm{L}^{-1}$ de $\mathrm{GA}_{3}$, enquanto as da 'Flame seedless' e 'Thompson seedless' atingiram calibre 19, pelos efeitos do tratamento com $10 \mathrm{mg} \cdot \mathrm{L}^{-1}$ de CPPU e $100 \mathrm{mg} \cdot \mathrm{L}^{-1}$ de $\mathrm{GA}_{3}$.

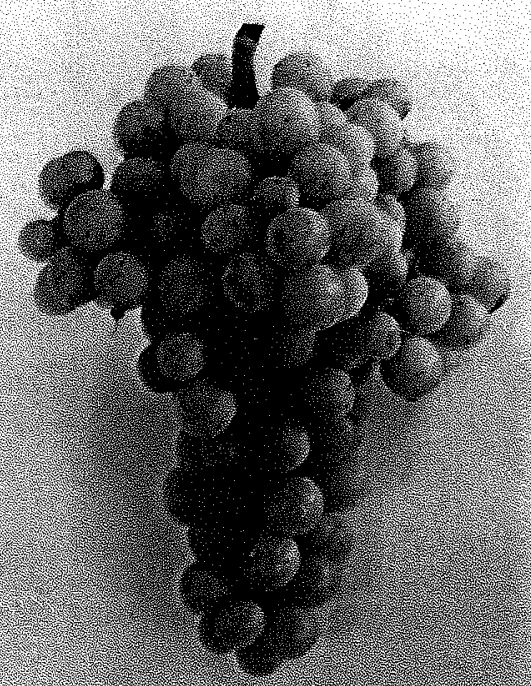

Figura 6 - Cachos da 'Thompson seedless', tratados com $10 \mathrm{mg} \cdot \mathrm{L}^{-1}$ de CPPU e $100 \mathrm{mg} \cdot \mathrm{L}^{-1}$ de $\mathrm{GA}_{3}$. ESALQ-USP, Piracicaba, 2002.

A Figura 7 demonstra uma tendência generalizada das bagas da cultivar Flame seedless possuírem teores de açucares maiores aos da 'Centennial seedless' e 'Thompson seedless'- visto através do Tratamento 1: CPPU (0) $+\mathrm{GA}_{3}(0)$; ou mesmo sob efeitos dos tratamentos com fitorreguladores. 


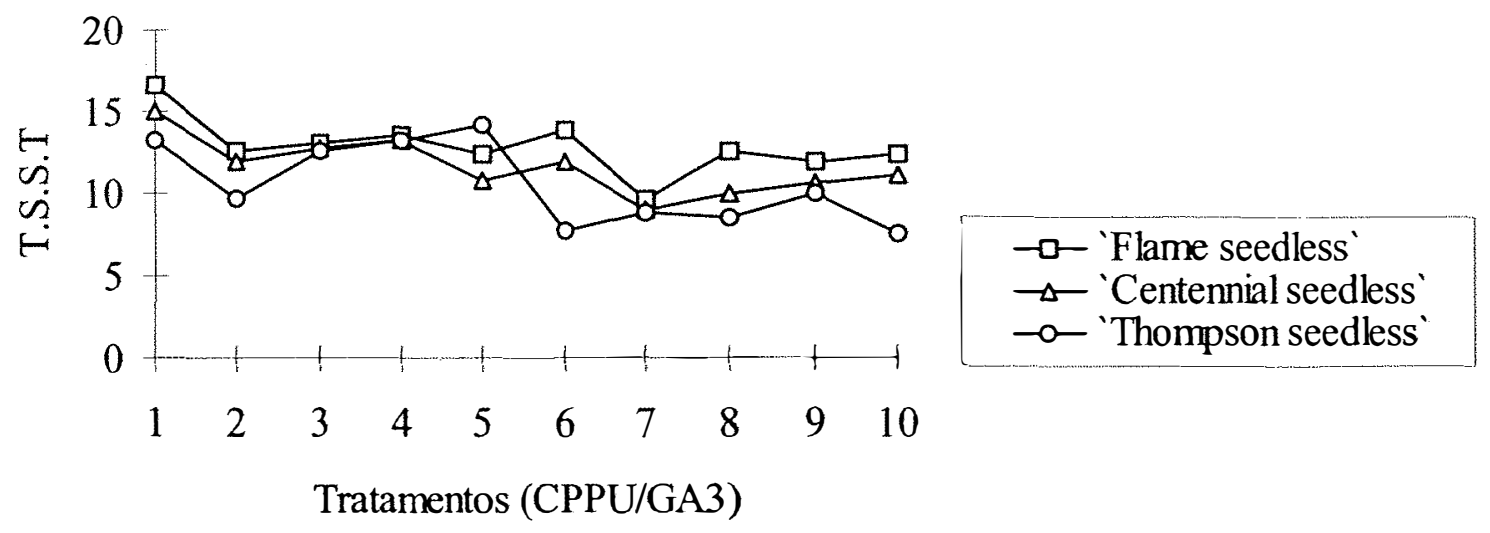

Figura 7 - Efeito do CPPU e GA $(T 1: 0-0 ;$ T2:0-25; T3:0-50; T4:0-75; T5:0-100; T6:10-0; T7:10-25; T8:10-50; T9:10-75 e T10:10-100 mg. $\mathrm{L}^{-1}$, respectivamente) sobre os teores de sólidos solúveis totais ( ${ }^{\circ} \mathrm{Brix}$ ) no mosto das cultivares Centennial seedless, Flame seedless e Thompson seedless. ESALQ-USP, Piracicaba, 2002.

Tratamentos com apenas ácido giberélico (T2 a T5) possuíram respectivamente para as cultivares Flame seedless, Centennial seedless e Thompson seedless, médias de 13,7, 12,8 e 12,4 ${ }^{\circ}$ Brix, e, que com associações com $10 \mathrm{mg} . \mathrm{L}^{-1}$ de CPPU (T6 a T10), reduziram-se ainda mais os teores de açucares para 12,1, 10,6 e 8,6 ${ }^{\circ}$ Brix; acentuando-se, portanto, as quedas no Brix com a adição do CPPU; fato, este, melhor visualizado pelo T7 (CPPU $10 \mathrm{mg} \cdot \mathrm{L}^{-1}$ $+\mathrm{GA}_{3} 25 \mathrm{mg} \cdot \mathrm{L}^{-1}$ ), quando os teores de açucares das três cultivares foram reduzidos em média para aproximadamente $9,1^{\circ}$ Brix.

Retardamentos na maturação, em termos da redução dos teores de sólidos solúveis totais têm sido constatados em diversos trabalhos (Diaz \& Maldonado, 1992; Reynolds et al., 1992; Rematales et al., 1995) pela aplicação conjunta do forchlorfenuron com o ácido giberélico.

Resultados semelhantes foram encontrados em 'Moscatel Rosada' quando se utilizou $\mathrm{GA}_{3}$ a $35 \mathrm{mg} \cdot \mathrm{L}^{-1}$, entretanto, em mistura com CPPU a 0, 2, 4, $6 \mathrm{mg} \cdot \mathrm{L}^{-1}$ ocorreu atraso na maturação dos frutos (Joublan et al. 1995), e Leão et 
al. (1999) encontraram diferenças de até oito dias no amadurecimento de bagas no primeiro ciclo de produção da cultivar Perlette, em Petrolina, PE, devido a combinação de $\operatorname{CPPU}\left(0,5,10\right.$ e $\left.20 \mathrm{mg} \cdot \mathrm{L}^{-1}\right)$ com $\mathrm{GA}_{3}\left(0,10\right.$ e $\left.40 \mathrm{mg} \cdot \mathrm{L}^{-1}\right)$.

\subsection{Conclusões}

As cultivares Centennial seedless, Flame seedless e Thompson seedless comportam-se diferentemente aos tratamentos com CPPU e GA, porém, a aplicação de $100 \mathrm{mg} \cdot \mathrm{L}^{-1}$ de $\mathrm{GA}_{3}$ de forma isolada para a 'Centennial seedless' e adicionada com $10 \mathrm{mg}^{-1} \mathrm{~L}^{-1}$ de CPPU para a 'Flame seedless' $\mathrm{e}$ 'Thompson seedless' foram as mais responsivas para o crescimento das bagas; e houve uma diminuição dos teores de sólidos solúveis totais no mosto das três cultivares, com a associação de niveis de fitorreguladores, retardando o amadurecimento das uvas. 


\section{FERTILIDADE DE GEMAS EM CULTIVARES DE UVAS APIRÊNICAS TRATADAS COM BENZYLADENINA E CYCOCEL}

\section{Resumo}

Os mercados para consumo de uvas apirênicas encontram-se largamente em expansão. Em via de regra, as cultivares introduzidas no Brasil não têm apresentado produtividades satisfatórias, principalmente devido à baixa fertilidade de suas gemas. O efeito da aplicação de chlormequat $(0,500$ e 1.000 $\left.\mathrm{mg} . \mathrm{L}^{-1}\right)$ combinados com um único nível de benzyladenina $(500 \mu \mathrm{M})$, seguidos de uma segunda época de aplicação de chlormequat $\left(0,50.000\right.$ e $\left.100.000 \mathrm{mg} \cdot \mathrm{L}^{-1}\right)$, foram estudados na fertilidade de gemas durante o ciclo de produção de Vitis vinifera (L.) 'Flame seedless'e 'Thompson seedless', instalados no município de Porto Feliz, SP. Para a 'Flame seedless', Chlormequat $\left(517,29 \mathrm{mg} \cdot \mathrm{L}^{-1}\right)$ combinado com a benzyladenina promoveram a fertilidade de $54,45 \%$ das gemas, quando aplicado durante o período da sua formação, datado 105 dias do início da brotação, obtendo-se uma melhor distribuição das gemas férteis ao longo das varas.

Palavras-chave: BA, CCC, vitis vinifera, citocinina, fisiologia da produção. 


\section{FRUIT BUDS OF SEEDLESS GRAPES IN APPLICATION WHITH BENZILADENINE AND CYCOCEL}

\section{Summary}

The market consumer of the seedless grapes to be expansive. Cultivars introduces in Brazil were show decrease in the produces owing fruitless of the buds. The effects of application of levels chlormequat $(0,500$ and 1.000 $\left.\mathrm{mg} \cdot \mathrm{L}^{-1}\right)$ in combination with single level of benzyladenine $(500 \mu \mathrm{M})$, followed by application of others levels chlormequat $\left(0,50.000\right.$ and $\left.100.000 \mathrm{mg} \cdot \mathrm{L}^{-1}\right)$ on the rate inflorescence formation during the second production cycle were studied in Vitis vinifera (L.) 'Flame seedless' and 'Thompson seedless', in vineyard, located in Porto Feliz, SP. Chlormequat $\left(517,29 \mathrm{mg} \cdot \mathrm{L}^{-1}\right)$ in combination with benzyladenine promoted inflorescence formation of the 'Flame seedless' $(54,45$ $\%)$ when applicator during the differentiation of the latent buds with 105 days after of the formation prune, and showed a distribution of the fertile buds in long of branches, which were cutting with twenty buds.

Key words: BA, CCC, Vitis vinifera, cytokines, physiology of production.

\subsection{Introdução}

A produção de uvas finas para mesa no Brasil está embasada nas cultivares de uvas com sementes, destacando-se a 'Itália' e suas mutações 'Rubi', 'Benitaka'. Frente à crescente demanda interna e para exportação de uvas apirênicas, principalmente para o mercado americano, ajustes no sistema de manejo objetivando uma melhor adaptação das cultivares já introduzidas tornam-se necessários, pois, em via de regra, essas cultivares apresentam excesso de vigor vegetativo, baixa fertilidade de gemas e de qualidade de 
cachos, resultando numa baixa produção (Camargo et al., 1997; Camargo, 1998).

Srinivasan \& Mullins (1976) citam que a formação de inflorescências em várias cultivares de uva envolve três estádios bem definidos: a presença do anlagen; a diferenciação do anlagen para primórdios de inflorescências e a sua diferenciação para flores, propriamente dita, durante a brotação das gemas.

Durante o ciclo da videira, balanços de giberelinas e citocininas tendem a aumentar em direção às citocininas, podendo-se otimizar este gradiente com produtos que inibam a ação das giberelinas (Kozlowski et al., 1990) e favorecer, desta forma, o florescimento. De acordo com Snirivasan \& Mullins (1980), as giberelinas estão envolvidas com a formação dos anlagens, contudo, atuando em uma fase posterior são prejudiciais para a formação de inflorescências por esses anlagens, diferenciando-os em gavinhas.

O chlormequat, também denominado cycocel, cloreto de clorocolina ou CCC, um inibidor da expansão e da divisão celular da região subapical de crescimento, reduz 0 alongamento dos internódios sem interromper 0 crescimento do meristema apical e tem sido utilizado para duas finalidades básicas: retardar o crescimento da planta e para atrasar a brotação, por bloquear a biossíntese de giberelinas (Kozlowski et al., 1990; Pires, 1998); e tem ação sinérgica na biossíntese de citocininas realizada pelo sistema radicular da videira (Srinivasan \& Mullins, 1980).

Dados da PANS (1973), de ensaios realizados em vários países, sobre o efeito da aplicação do CCC em plantas frutíferas, e especificamente para uva citam que 200-300 mg. $\mathrm{L}^{-1}$ reduzem a formação de uva-pedra, bem como o comprimento das varas, provocando, contudo, diminuição dos teores de sólidos solúveis totais das bagas; $500-1.000 \mathrm{mg} \cdot \mathrm{L}^{-1}$ aplicadas durante o florescimento aumentam o número e os pesos individuais das bagas, resultando cachos melhores; $1.200 \mathrm{mg} . \mathrm{L}^{-1}$ aplicada antes do florescimento aumenta a produção, os cachos são mais compactos e diminui a formação de bagas pequenas; 1.600 $\mathrm{mg} . \mathrm{L}^{-1}$ aplicada uma a três semanas antes do florescimento reduz a queda de 
botões florais, aumenta a produção e reduz de 10-15 \% o comprimento de sarmentos; e, Tukey \& Fleming (citados por Pires, 1998), observaram um aumento no pegamento de frutos da cultivar $V$. vinifera (L.) Himrod seedless com $2.000 \mathrm{mg} \cdot \mathrm{L}^{-1}$ de CCC.

Motoike et al. (1996) obtiveram aumentos na fertilidade de gemas da cultivar pirênica $V$. vinifera (L.) Itália com aplicação de CCC em até $200 \mathrm{mg} \cdot \mathrm{L}^{-1}$; Albuquerque (1998) ao aplicar CCC (1.500 mg. $\left.\mathrm{L}^{-1}\right)$ em videiras, observou a redução do vigor dos ramos e alterações das concentrações de nutrientes nas plantas, com reflexos positivos na fertilidade das gemas. Lilov \& Andonova (1976) obtiveram incrementos, na fertilidade de gemas da cultivar $V$. vinifera (L.) Cardinal com $90.000 \mathrm{mg} \cdot \mathrm{L}^{-1}$, aplicada junto à poda de frutificação.

O presente trabalho teve por objetivo estudar a taxa de fertilidade de gemas das Vitis vinifera (L.) 'Flame seedless'e 'Thompson seedless', sob efeito dos fitorreguladores CCC e benzyladenina (BA).

\subsection{Material e Métodos}

Em agosto de 2000 as plantas das três cultivares foram podadas com três a quatro gemas para formação de esporões, analisando-se, em seguida, a fertilidade de gemas do primeiro ciclo produtivo.

O experimento foi executado sob as condições edafoclimáticas do município de Porto Feliz, SP- coordenadas geográficas de $23^{\circ} 12^{\prime} \mathrm{S}, 47^{\circ} 31^{\prime} \mathrm{W}$ e altitude de $540 \mathrm{~m}$-, na propriedade do Sr. Antonio Portronieri, durante o segundo ciclo de produção das cultivares Flame seedless e Thompson seedless.

Cada cultivar foi enxertada em 9 plảntas do IAC-572 'Jales' em agosto de 1999, plantadas no espaçamento 3,0×3,60 m, e instaladas em sistema de latada, sendo em agosto de 2000 podadas para formação e para a análise do primeiro ciclo produtivo, mantendo-se nas plantas esporões com três a quatro gemas. A segunda poda de produção foi realizada em 20 de março de 2001. Em cada época, após as podas, aplicou-se Cianamida Hidrogenada para quebra de 
dormência e uniformidade da brotação- Dormex a $5 \%$ na primeira poda e 3,5 \% na segunda; tendo-se adotado esta menor concentração por se verificar uma tendência de brotações das gemas pelo período de sete meses mantido para o amadurecimento dos ramos.

A fertilidade de gemas das duas épocas de produção foi tomada em toda a extensão da planta, pelo número de brotos e inflorescências na coroa e varas, respectivamente em 25 de setembro de 2000 e 03 de maio de 2001.

No primeiro ciclo, além da avaliação da fertilidade de gemas (relação: número de cacho/número de broto) apresentada pelas 9 plantas delineadas para cada cultivar (30 varas/planta), analisou-se a qualidade de cachos pelo comprimento, largura e peso- computados de uma parcela com 10 cachos (com 12,6 ${ }^{\circ}$ Brix), nos quais se aplicou quando com 15 dias do pleno florescimento $\mathrm{GA}_{3}$ a $50 \mathrm{mg} \cdot \mathrm{L}^{-1}$ e CPPU (Forchlorfenuron) a $10 \mathrm{mg} \cdot \mathrm{L}^{-1}-$, e, ainda, pelo comprimento, largura e peso de bagas- tomadas dé 100 bagas amostradas aleatoriamente de cinco cachos que possuiam os pesos mais próximos aos da média dos 10 cachos amostrados.

No segundo ciclo de produção a fertilidade de gemas foi avaliada ao longo de varas com 20 gemas. Os cachos produzidos foram coletados em estádios fenológicos de chumbinho/ervilha, tomando-se seus comprimentos e pesos da matéria fresca; e foram computados o número de gemas/ha e de brotos/gema, ou seja, o porcentual de brotação das gemas.

Durante o segundo ciclo vegetativo, com o objetivo de incrementar niveis de citocininas nas plantas das duas cultivares, com vistas a um aumento da fertilidade de gemas, foram adotados os seguintes procedimentos:

a) por uma perspectiva dos niveis endógenos nas plantas, adotou-se a prática de despontes sucessivos das brotações emergentes durante todo o ciclo, ou seja, ramos ao atingirem 20 gemas foram despontados, eliminando-se todos os netos- exceto os das posições $18^{a}, 19^{a}$ e $20^{a}$ gemas, que mantidos, foram despontados com o crescimento até três nós e, desta forma, todas as demais rebrotas, devido a um novo desponte-, até o amadurecimento completo dos ramos. Objetivou-se com a supressão das terminações apicais- os sítios de 
produção de auxinas e giberelinas-, elevar, comparativamente, os teores de citocininas nas plantas, produzidas nas terminações radiculares (segundo Kende \& Sitton, 1967, e Srinivasan \& Mullins, 1980);

b) e, por uma perspectiva exógena, em 19 de dezembro de 2000ou seja, aos 105 dias do início da brotação, dentro de um ciclo vegetativo de 196 dias (brotação/poda)-, foram aplicados três niveis de CCC $\left(0,500\right.$ e $1.000 \mathrm{mg} \cdot \mathrm{L}^{-1}$ - "Tuval": chlormequat $10 \%$, Microquímica S/A.) combinados com o único nível de $\mathrm{BA}$ a $500 \mu \mathrm{M}$ e, em 20 de dezembro de 2000, foram repetidos os tratamentos, ou seja, nas épocas de maior insolação do ano. Em 22 de março de 2001 (após a aplicação de Dormex a 3,5 \%), niveis maiores de CCC: 0, 50.000 e 100.000 $\mathrm{mg} \cdot \mathrm{L}^{-1}$, foram aplicados às gemas na forma de pincelamento. No dia 27 do corrente mês, as gemas encontrando-se no estádio fenológico de algodão, foram novamente expostas às últimas concentrações de CCC.

O experimento foi conduzido em blocos ao acaso, em esquema fatorial tipo $3 \times 3 \times 2$, com três repetições e uma planta por parcela, onde se aplicou o CCC com a BA, numa primeira época; e posteriormente, os três últimos niveis de CCC sem a BA (segunda época), alocando-se 10 varas dentro de cada planta para cada nivel de CCC aplicado. Para fins de análise estatística, os dados da fertilidade de gemas (número de cacho/número de broto) e da taxa de brotação (número de brotos/número total de gemas) foram interpretados por meio de análise de variância, teste de médias e regressão, baseando-se para a escolha dos modelos a significância dos coeficientes de regressão, utilizando-se o teste " $t$ " $(\alpha<0,05)$ e o coeficiente de determinação $\left(R^{2}>0,70\right)$. 


\subsection{Resultados e Discussão}

Observa-se, pela Análise de Variância (Tabola 2), diferenças significativas para cultivares e segunda época de aplicação de CCC, interações da 'Flame seedless' com a primeira época de aplicação (CCC + BA) em relação à variável fertilidade de gemas, e da 'Flame seedless' e 'Thompson seedless' com a segunda época de aplicação (CCC), para a taxa de brotação das gemas.

Tabela 2. Análise de variância da fertilidade de gemas apresentada pelas $V$. vinifera (L.) 'Flame seedless' e 'Thompson seedless' no segundo ciclo de produção. ESALQ-USP, Piracicaba, 2002.

\begin{tabular}{|c|c|c|c|}
\hline \multirow[t]{2}{*}{ Fonte de variação } & \multirow[t]{2}{*}{$\mathrm{GL}$} & \multicolumn{2}{|c|}{ Quadrados Médios } \\
\hline & & Fertilidade de Gemas & Taxa de Brotação \\
\hline Cultivar & 1 & $0,3491^{*}$ & $0,5432^{\star \star}$ \\
\hline Época 1 & 2 & 0,0733 & 0,0087 \\
\hline Época 2 & 2 & 0,0894 * & $0,5307^{\star \star}$ \\
\hline (Cultivar * Época 1) & $(2)$ & $(0,1126 *)$ & $(0,0029)$ \\
\hline 'Flames sds' - Eq. Quadr. & 1 & $0,3633^{\star \star}$ & --- \\
\hline (Cultivar * Época 2) & $(2)$ & $(0,0396)$ & $\left(0,1728^{\star \star}\right)$ \\
\hline 'Flame sds' - Eq. Lin. & 1 & --- & $1,2761^{\star \star}$ \\
\hline 'Thompson sds' - Eq. Lin. & 1 & ---- & $0,0944^{*}$ \\
\hline Cultivar * Época 1 * Época 2 & 4 & 0,0137 & 0,0028 \\
\hline Época 1 * Época 2 & 4 & 0,0194 & 0,0352 \\
\hline \multirow[t]{2}{*}{ Resíduo } & 36 & 0,0223 & 0,0215 \\
\hline & $\mathrm{CV}(\%)=$ & 50,84 & 27,29 \\
\hline
\end{tabular}

${ }^{\star \star} \alpha<0,01 ;{ }^{\star} \alpha<0,05$

A Figura 8, refere-se ao crescimento dos ramos das cultivares Flame seedless e Thompson seedless, que segundo Huglin (1986), são parâmetros adequados para aferir o vigor vegetativo da videira. 


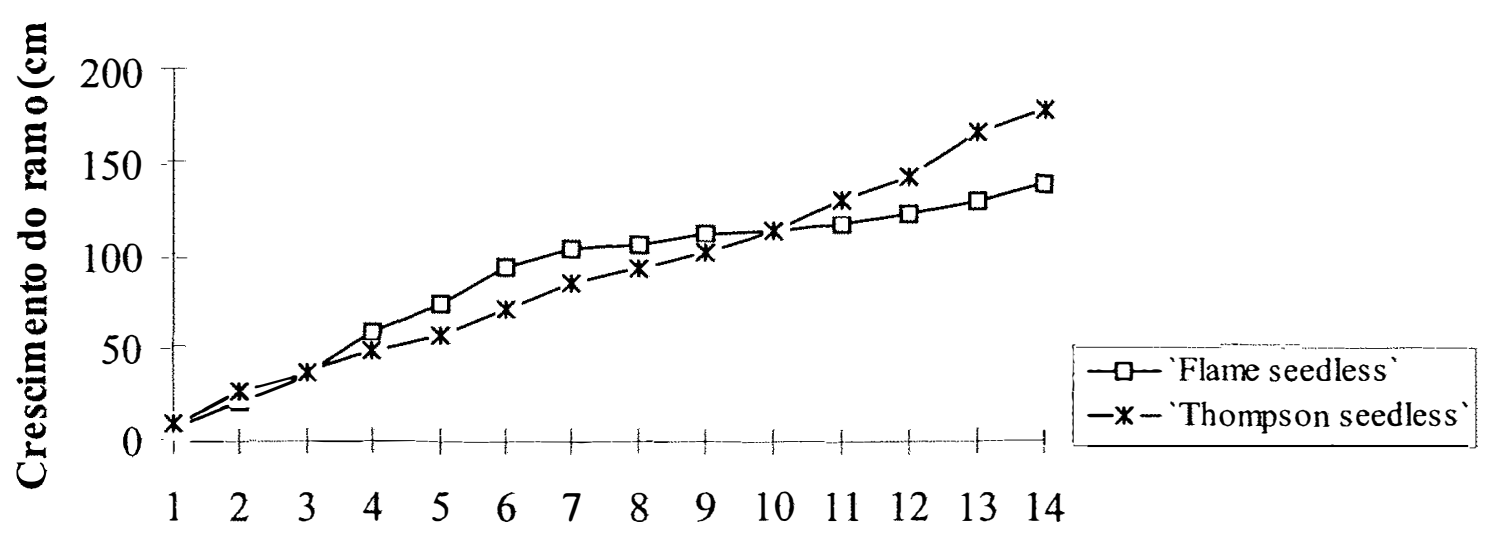

Data

Figura 8 - Crescimento dos ramos $(\mathrm{cm})$ das cultivares Flame seedless e Thompson seedless destinados ao segundo ciclo produtivo. ESALQ-USP, Piracicaba, 2002. (Legenda: 1: 12-19/09; 2: 20-26/09; 3: 27/09-03/10; 4: 4-10/10; 5: 11-17/10; 6:18-24/10; 7:25-31/10; 8: 1-7/11; 9: 8-14/11; 10: 15-21/11; 11: 2228/11; 12: 29/11-5/12; 13: 6-12/12; 14: 13-19/12/2000).

Observa-se que a 'Flame seedless' apresentou maiores surtos de crescimento até os 77 dias (31/10/00) da poda de formação, com taxas médias de crescimento de $5 \mathrm{~cm} / \mathrm{semana}$ até as datas de aplicação dos fitorreguladores (19/12/00); fato não verificado para a 'Thompson seedless', que apresentou uma linearidade nas taxas de crescimento sob as mesmas condições de manejo, sendo, portanto, comparativamente, a mais vigorosa.

A Tabela 3 descreve as dimensões das plantas, através dos diâmetros das varas despontadas e dos troncos, a $10 \mathrm{~cm}$ de altura da enxertia, tomados na época de coleta dos cachos da segunda produção (24/05/01).

A Tabela 4, refere-se ao comprimento $(12,80 \pm 5,12 \mathrm{~cm})$ e peso da matéria fresca $(18,90 \pm 15,27 \mathrm{~g})$ de um total de 108 cachos avaliados em estádios fenológicos de chumbinho/ervilha no segundo ciclo da 'Flame seedless'; após a aplicação de CCC com BA. Observando-se, também, a formação de rácimos de boa qualidade (Figura 9). 
Tabela 3. Crescimento de plantas (diâmetros de varas e troncos) tomados na época do florescimento do segundo ciclo produtivo das cultivares Flame seedless e Thomposon seedless. ESALQ-USP, Piracicaba, 2002.

Diâmetros

\begin{tabular}{cccccc} 
Cultivares & Época 1 & \multicolumn{2}{c}{ Vara $(\mathrm{mm})$} & \multicolumn{2}{c}{ Tronco $(\mathrm{cm})$} \\
& & média & Sm & média & sm \\
\hline Flame seedless & nível 1 & 8,43 & 1,61 & 9,50 & 0,77 \\
& nível 2 & 7,88 & 1,37 & 9,67 & 0,76 \\
& nível 3 & 9,02 & 1,69 & 11,57 & 0,67 \\
Thompson seedless & nível 1 & 9,07 & 1,56 & 11,62 & 2,13 \\
& nível 2 & 8,42 & 1,44 & 8,40 & 0,87 \\
& nível 3 & 8,59 & 1,12 & 11,15 & 2,04 \\
\hline
\end{tabular}

Tabela 4. Número de cachos avaliados, comprimento e peso da matéria fresca de cachos em estádios fenológicos chumbinho/ervilha, coletados da $V$. vinifera (L.) 'Flame seedless', sob efeitos do tratamento com CCC (500 mg.L $\left.{ }^{-1}\right)$ e BA $(500 \mu \mathrm{M})$. ESALQ-USP. Piracicaba, 2002.

\begin{tabular}{cccc}
\hline $\begin{array}{c}\text { Tratamento } \\
\text { avaliados }\end{array}$ & $\begin{array}{c}\text { Cachos } \\
(\mathrm{cm})\end{array}$ & $\begin{array}{c}\text { P.M.F. } \\
(\mathrm{g})\end{array}$ \\
\hline CCC $(500 \mathrm{ppm})$ & & 12,80 & 18,96 \\
+ & 108 & $( \pm 5,12)$ & $( \pm 15,27)$ \\
BA $(500 \mu \mathrm{M})$ & & & \\
\hline P.M.F.: Peso da Matéria Fresca & &
\end{tabular}

As Figuras 10 e 11 retratam, respectivamente, cachos em plantas da 'Flame seedless' e da 'Thompson seedless', situadas na área experimental, durante o primeiro ciclo produtivo, demonstrando a boa qualidade dos cachos obtidos neste período. 


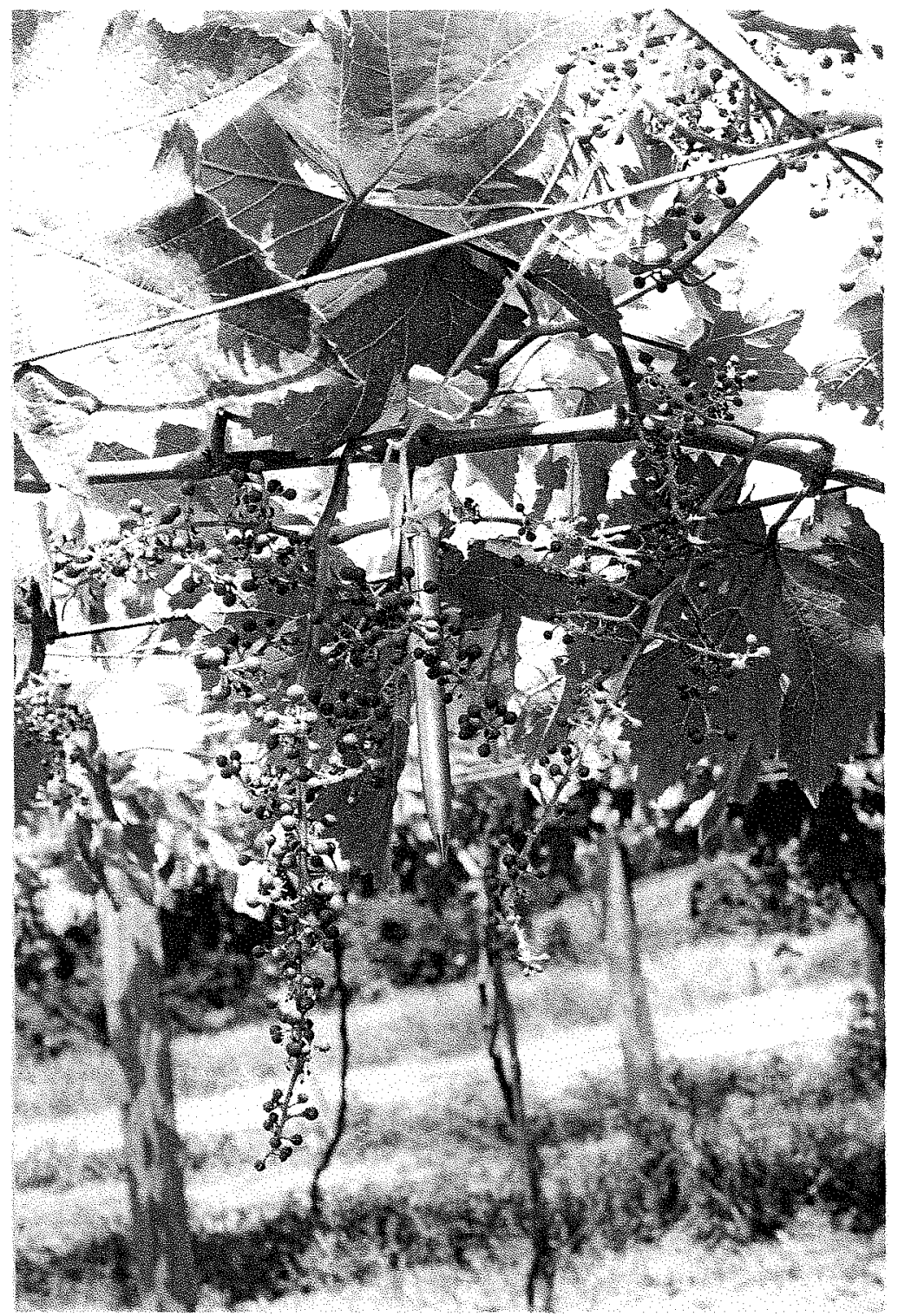

Figura 9 - Estádio fenológico chumbinho/ervilha dos cachos das cultivares apirênicas, verificados durante a avaliação no segundo ciclo de produção. ESALQ-USP, Piracicaba, 2002.

Para os níveis da primeira época de $\operatorname{CCC}\left(0,500\right.$ e $1.000 \mathrm{mg} \cdot \mathrm{L}^{-1}$, adicionados a $500 \mu \mathrm{M}$ BA), a dose nula, ou então somente com a aplicação de $500 \mu \mathrm{M}$ de $\mathrm{BA}$, a fertilidade de gemas foi de $28,22 \%$, evidenciando a necessidade da aplicação conjunta do CCC com a BA para o incremento da 
fertilidade de gemas da 'Flame seedless', que a $517,29 \mathrm{mg} \cdot \mathrm{L}^{-1}$ (mais os $500 \mu \mathrm{M}$ de BA), promoveram a diferenciação de $54,45 \%$ das gemas (Figura 12).

Motoike et al. (1996) obtiveram aumentos na fertilidade de gemas da 'Itália' com aplicação de CCC em até $200 \mathrm{mg} \cdot \mathrm{L}^{-1}$; Albuquerque (1998) ao aplicar CCC (1.500 mg.. $\left.{ }^{-1}\right)$ em videiras, observou a redução do vigor dos ramos e alterações das concentrações de nutrientes nas plantas, com reflexos positivos na fertilidade das gemas; e Camargo et al. (1999), trabalhando do com a cultivar Thompson seedless, na região noroeste paulista, adotaram a prática da desponta de ramos e obtiveram aumentos na fertilidade de gemas com a aplicação conjunta de 100 à $500 \mathrm{mg}^{-\mathrm{L}^{-1}}$ de CCC, corroborando as atuais observações.

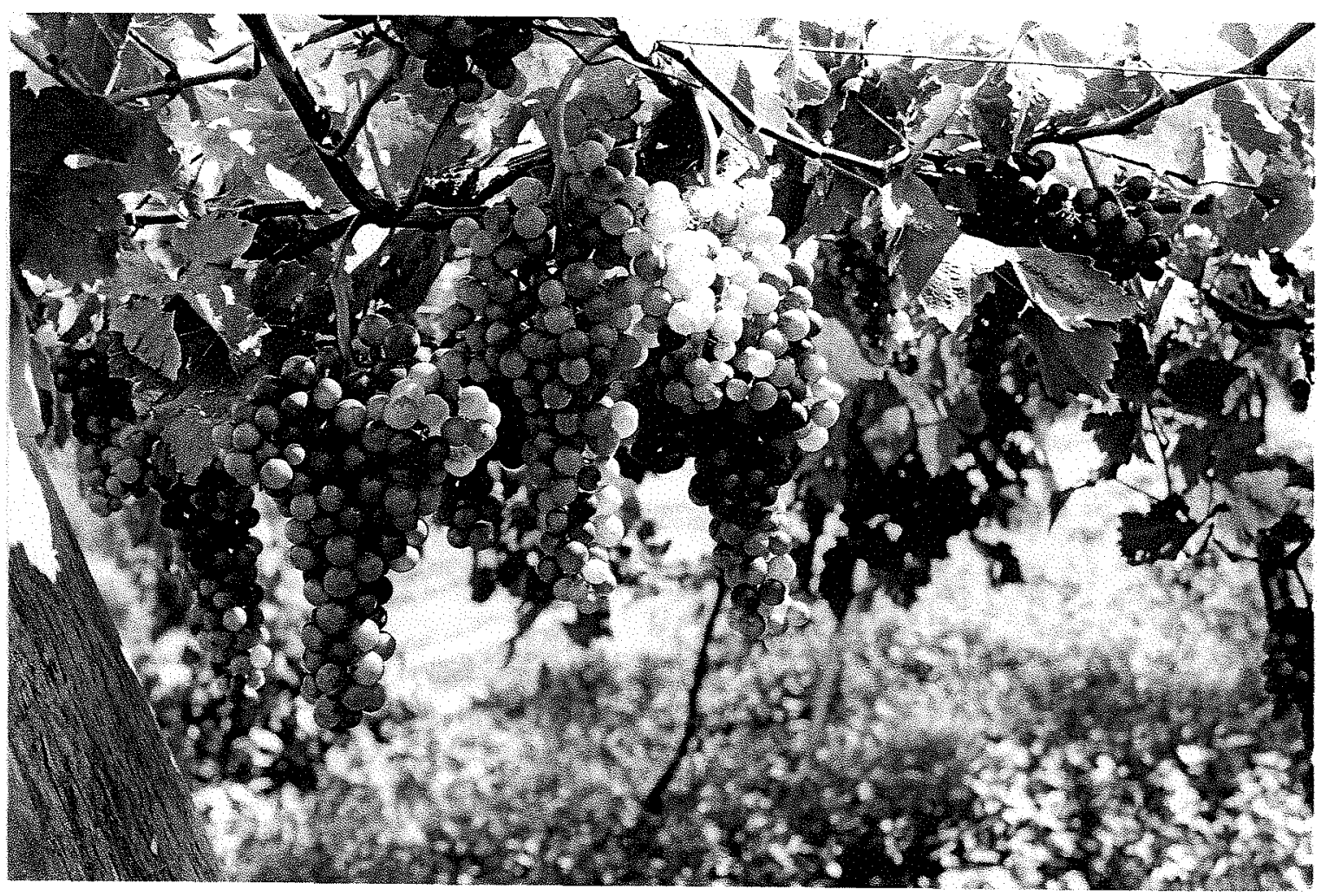

Figura 10 - Cachos em plantas da V. vinifera (L.) 'Flame seedless' no primeiro ciclo produtivo. ESALQ-USP, Piracicaba, 2002. 
A fertilidade de gemas de $54,45 \%$ apresentada pela 'Flame seedless` (Figura 12), foi acompanhada por uma distribuição regular das gemas florais ao longo das varas com 20 gemas, onde $41 \%$ das gemas férteis encontravam-se até a $10^{\mathrm{a}}$ posição, e $71 \%$ até a $15^{\mathrm{a}}$ (Figura 13). A indução da fertilidade das gemas mais basais em cultivar apirênica, pelo uso do CCC, pôde também ser observado por Camargo et al. (1999) com a 'Thompson seedless'.

Há relatos de que o florescimento em videira é inibido pela ação de giberelinas (Srinivasan \& Mullins, 1980), ou, quando sua biossintese for bloqueada pela ação de retardadores de crescimento, como o CCC (Sugiura et al., 1976; Kozlowski et al., 1990).

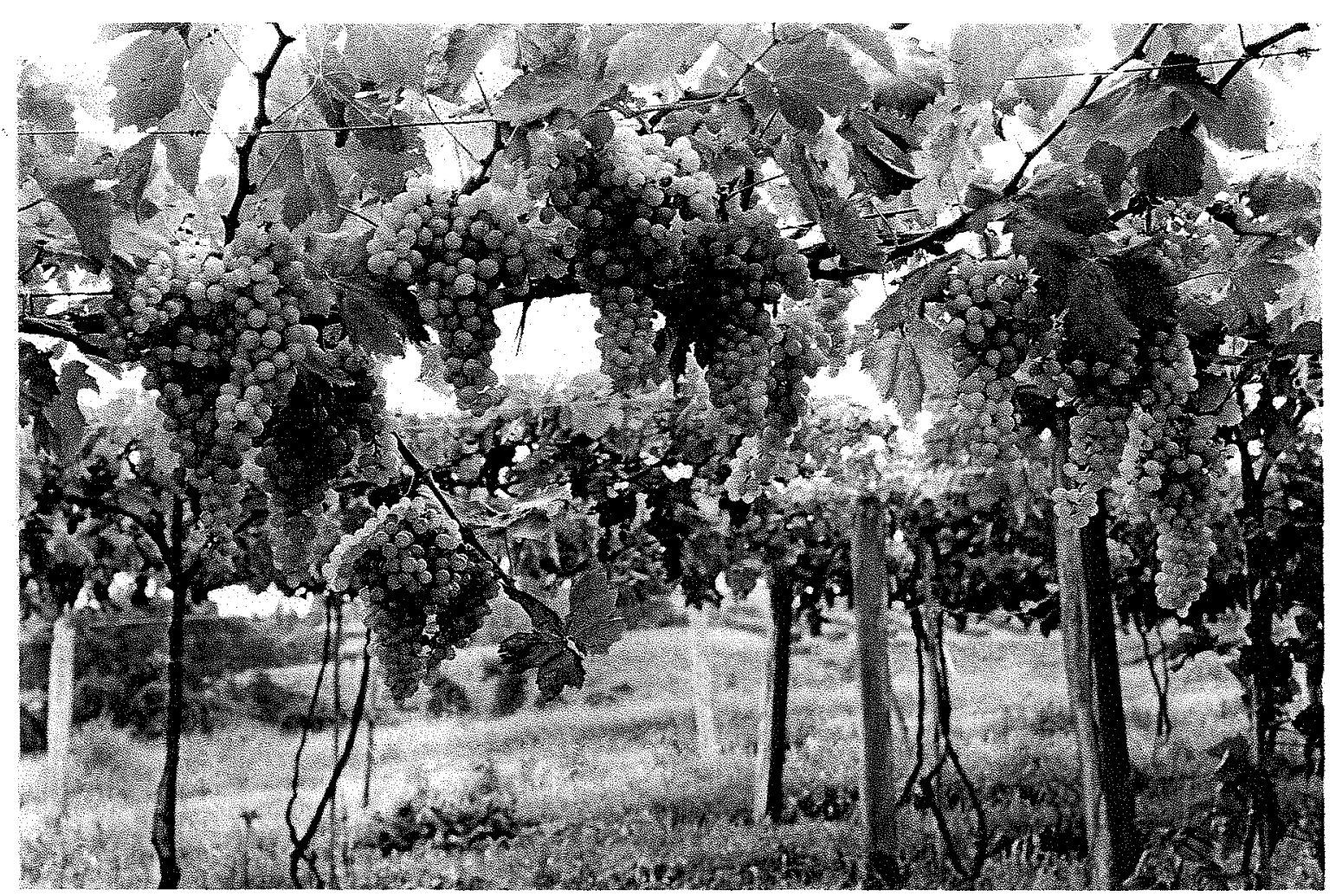

Figura 11 - Cachos em plantas da V. vinifera (L.) 'Thompson seedless' no primeiro ciclo produtivo. ESALQ-USP, Piracicaba, 2002.

Snirivasan \& Mullins $(1976 ; 1978 ; 1980)$ relatam que o processo de formação floral envolve três etapas: a formação do anlagen, sua diferenciação em primórdios florais e, depois, a formação propriamente dita das flores; sendo 
que primórdios de inflorescência e gavinhas desenvolvem-se em órgãos maduros durante a brotação das gemas na próxima estação, e as duas primeiras etapas durante o desenvolvimento dos ramos.

Os mesmos autores (Srinivasan \& Mullins, 1980) trabalhando sob condições controladas de casa de vegetação, observaram à partir da aplicação seqüencial de CCC e BA em gemas latentes de $V$. vinifera (L.) 'Muscat de Alexandria', a formação normal do anlagen, de primórdios de inflorescências e de gavinhas.

$Y^{`}$ Flame seedless $^{`}=0,282244+0,0010139 x-0,00000098 x^{2} \quad R^{2}=1,00$

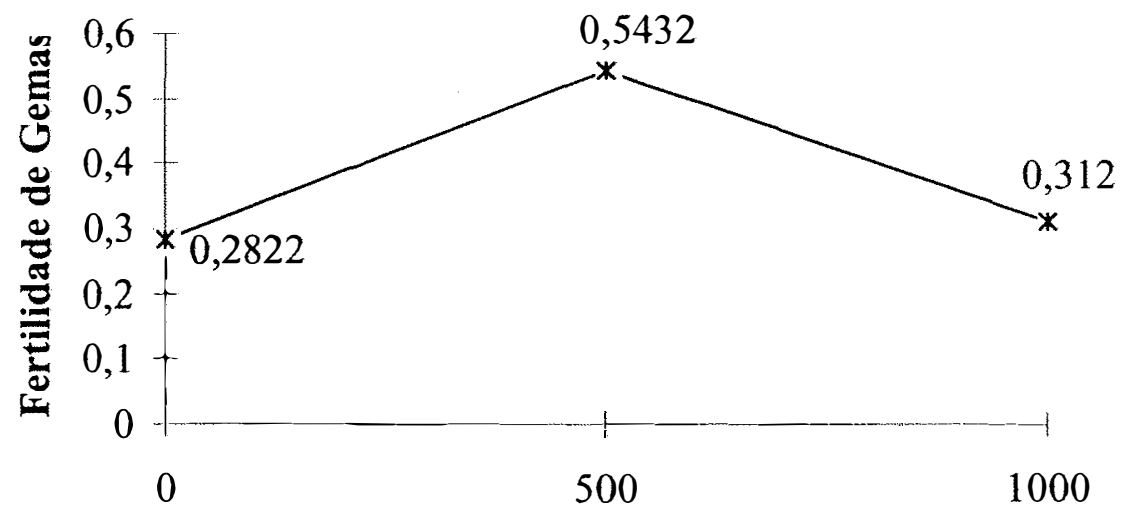

$\mathrm{CCC}(\mathrm{mg} / \mathrm{L})$

Figura 12 - Fertilidade de gemas verificada no segundo ciclo produtivo da $\mathrm{V}$. vinifera (L.) 'Flame seedless' sob efeito dos tratamentos com CCC $(0,500$ e $1000 \mathrm{mg} . \mathrm{L}^{-1}$ ) adicionados a $500 \mu \mathrm{M}$ de BA. ESALQ-USP, Piracicaba, 2002.

Pelos resultados, favorecidos com a aplicação do CCC com a BA ainda durante a formação/amadurecimento dos ramos (105 dias após o início da brotação, em um ciclo de 196 dias), supõe-se que houve uma interação positiva entre os fitorreguladores com as gemas florais, em vias, ou não totalmente diferenciadas, mas aptas para a diferenciação floral (possivelmente anlagens, primórdios de inflorescências e/ou gavinhas), atingindo-se $54,45 \%$ da diferenciação observada. 


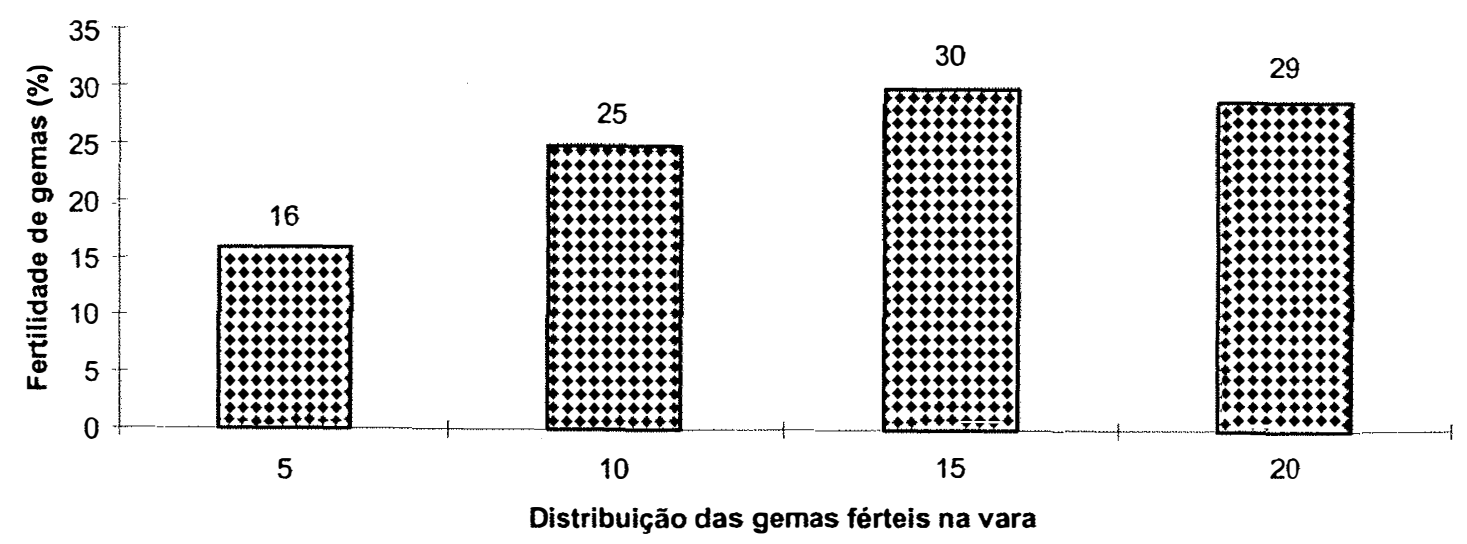

Figura 13 - Distribuição das gemas férteis nas varas (\%) da V. vinifera (L.) 'Flame seedless' no segundo ciclo produtivo, após tratamento com CCC (500 ppm) e BA (500 $\mu \mathrm{M})$. ESALQ-USP, Piracicaba, 2002.

Em tese, outro fator que possivelmente elevou os gradientes endógenos de citocininas em relação aos demais fitormônios de crescimento, como giberelinas e auxinas- seguramente ligadas à dominância apical das brotações das cultivares apirênicas-, foram as despontas dos netos remanescentes, situados da $18^{\mathrm{a}}$ a $20^{\mathrm{a}}$ gemas, e os das subseqüentes rebrotas, durante todo o ciclo vegetativo (Figura 14). Segundo Kende \& Sitton (1967), as terminações radiculares são sítios de produção de citocininas na planta; logo, com a manutenção do sistema radicular e a supressão das terminações dos brotos, pôde-se favorecer gradientes de citocininas na 'Flame seedless', com resultantes à uma maior diferenciação floral.

Tecido meristemático, naturalmente é totipotente, e quanto menor for o grau de especialização de um determinado tecido, torna-se mais fácil retrocedê-lo a um estádio meristemático (embrionário), via efeitos hormonais (Torres \& Caldas, 1990). O potencial de dediferenciação de gavinhas e sua diferenciação para inflorescências pelo uso de citocininas foi demonstrado por Srinivasan \& Mullins (1978) quando aplicaram BA ou 6-(benzylamino)-9-(2tetrahydropyranyl)-9H-purine (PBA) em ápices de gavinhas cultivadas em meio 
líquido sob agitação, observando-se desenvolvimentos normais de cálice, corola, estames e pistilos, porém sem atingir as etapas de micro e macrosporogênese.

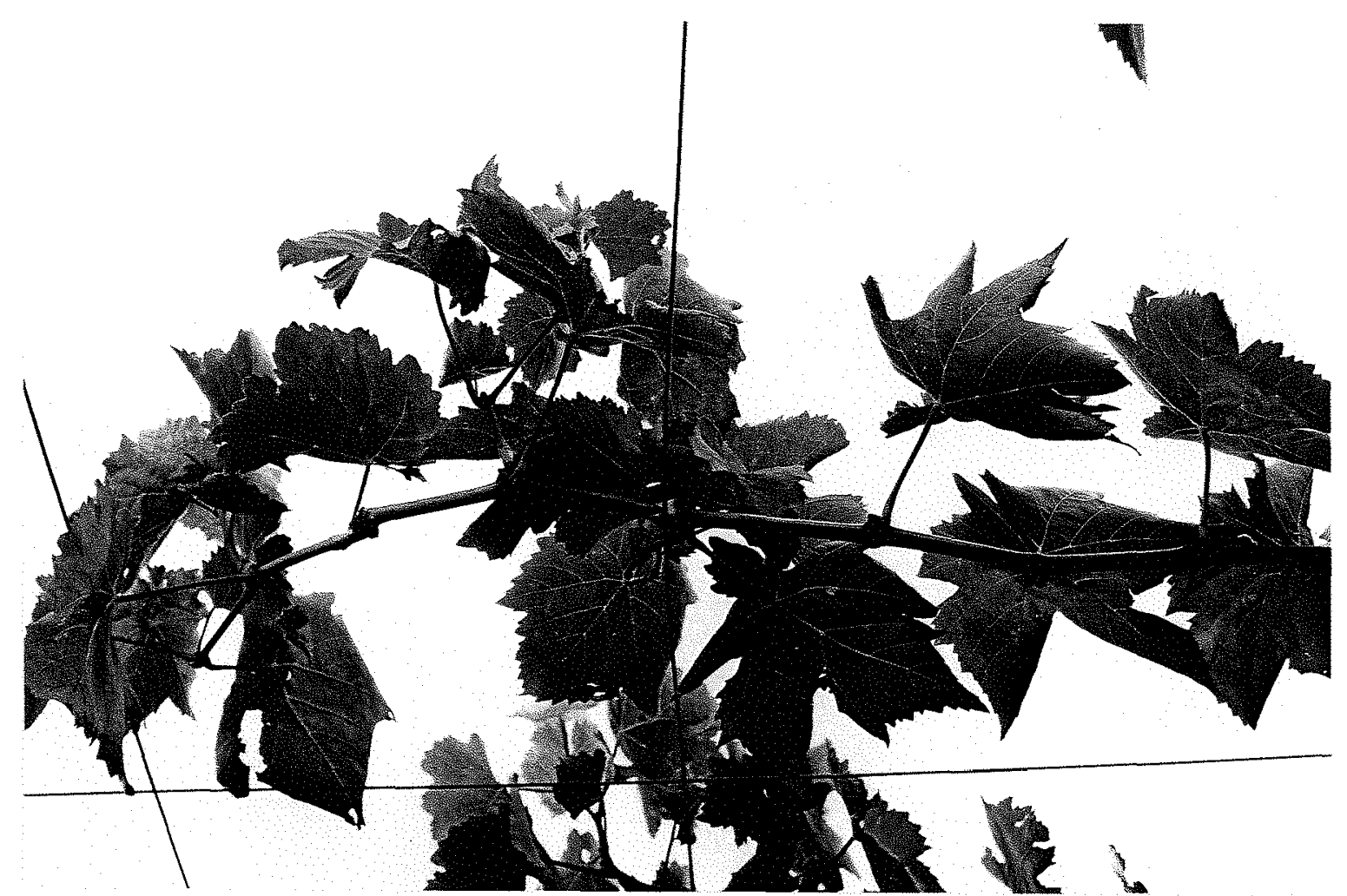

Figura 14 - Ramos despontados na $20^{\mathrm{a}}$ gema, com despontas sucessivas dos netos deixados da $18^{\mathrm{a}}$ à $20^{\mathrm{a}}$ gemas. ESALQ-USP, Piracicaba, 2002.

Skene (1970), estudando o efeito do CCC durante o crescimento radicular e sua relação com níveis de citocininas encontrados na seiva de $\mathrm{V}$. vinifera (L.) 'Cabernet sauvignon', verificou aumentos dos gradientes de citocininas com a aplicação do CCC; sendo que a atividade de citocininas na seiva foi potencializada na presença do CCC, permitindo-Ihe concluir sobre uma ação positiva do CCC na biossintese de citocininas nas raízes desta cultivar.

A Figura 15, referente à fertilidade de gemas (número de cacho/número de broto) dos dois ciclos produtivos das cultivares, demonstra que mesmo com a aplicação dos tratamentos, ocorreram quedas na taxa de fertilidade de gemas das duas cultivares; apresentando a 'Flame seedless' e a 'Thompson seedless', respectivamente variações de 69,86 \% e 41,34\%. 
Supõe-se que a queda de fertilidade de gemas do primeiro para o segundo ciclo produtivo das cultivares pode estar relacionada a um maior crescimento vegetativo da parte aérea das plantas em comparação ao do sistema radicular, favorecendo, assim, gradientes hormonais de crescimento (auxinas/giberelinas) em relação aos de citocininas; e, que, mesmo com as despontas realizadas, mais os tratamentos com fitorreguladores, não se atingiu indices ótimos de fitormônios suficientemente adequados para a elevação ou manutenção das taxas de fertilidade de gemas verificadas no primeiro ciclo produtivo.

Pelo teste de média (Tukey: $\alpha<0,05$ - Tabela 5), verifica-se que para a segunda época de aplicação de $\operatorname{CCC}\left(0,50.000\right.$ e $\left.100.000 \mathrm{mg} \cdot \mathrm{L}^{-1}\right)$ a ausência do produto (dose zero) proporcionou a menor taxa de fertilidade de gemas: $21,80 \%$; contrariamente aos $34 \%$ vistos pela aplicação do produto. Lilov \& Andonova (1976) obtiveram resultados positivos com a aplicação de CCC (90.000 mg. $\left.\mathrm{L}^{-1}\right)$ após a poda de frutificação; contudo, os níveis de $50.000 \mathrm{mg} \cdot \mathrm{L}^{-1}$ e de $100.000 \mathrm{mg} \cdot \mathrm{L}^{-1}$ de CCC não mantiveram interações significativas em relação à fertilidade das gemas para com quaisquer das cultivares avaliadas no presente trabalho.

A diferença significativa (Teste Tukey, $\alpha<0,05$ - Tabela 5) ocorrida entre os três níveis da segunda época de aplicação, indica que o CCC tem mobilidade baixa ou nula na videira, ou que, se ocorrida, a sua translocação não foi suficientemente significativa para que seu efeito sobre a fertilidade de gemas fosse constatado.

Observa-se pela Figura 16, referente à taxa de brotação do 'Flame seedless' e 'Thompson seedless', que para ausência do CCC, as cultivares mantiveram taxas próximas a $69 \%$ de brotação das gemas, e que a da 'Flame seedless' foi menor do que a da 'Thompson seedless' sob efeito dos tratamentos com até $100.000 \mathrm{mg} \cdot \mathrm{L}^{-1}$ de CCC. 


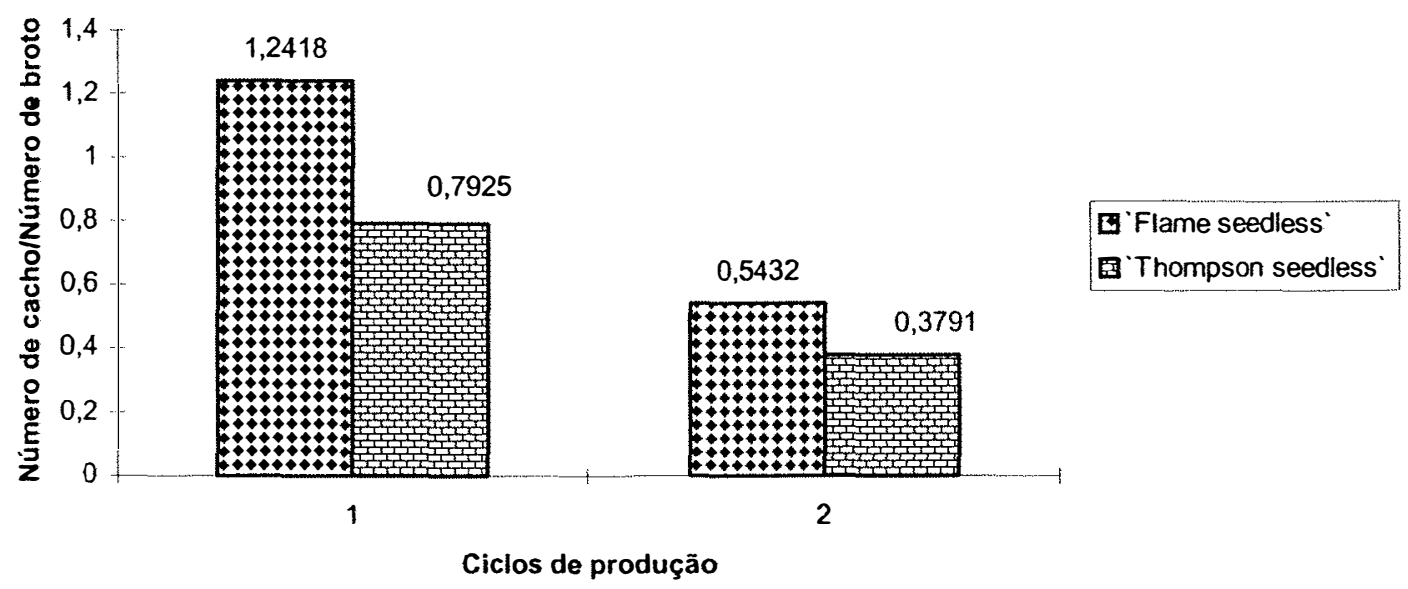

Figura 15 - Fertilidade de gemas (número de cacho/número de broto) verificada nos dois ciclos produtivos das $V$. vinifera (L.) 'Flame seedless' e 'Thompson seedless'. ESALQ-USP, Piracicaba, 2002.

Tabela 5. Teste Tukey para segunda época de aplicação dos níveis de CCC (em mg. $\mathrm{L}^{-1}$ ), para a fertilidade de gemas. ESALQ-USP, Piracicaba, 2002.

\begin{tabular}{lc}
\hline CCC & Fertilidade de gemas \\
0 & $0,2180 \mathrm{~b}$ \\
50.000 & 0,3480 a \\
100.000 & $0,3302 \quad$ a \\
\hline
\end{tabular}

Médias seguidas por letras distintas diferem $(\alpha<0,05$ - D.M.S. $=0,1249)$. 
$Y^{\prime}$ Flame seedless $^{\prime}=0,703031-0,0000053 x \quad R^{2}=0,98$

$Y^{\prime}$ Thompson seedless $^{\prime}=0,709781-0,0000014 x \quad R^{2}=0,74$

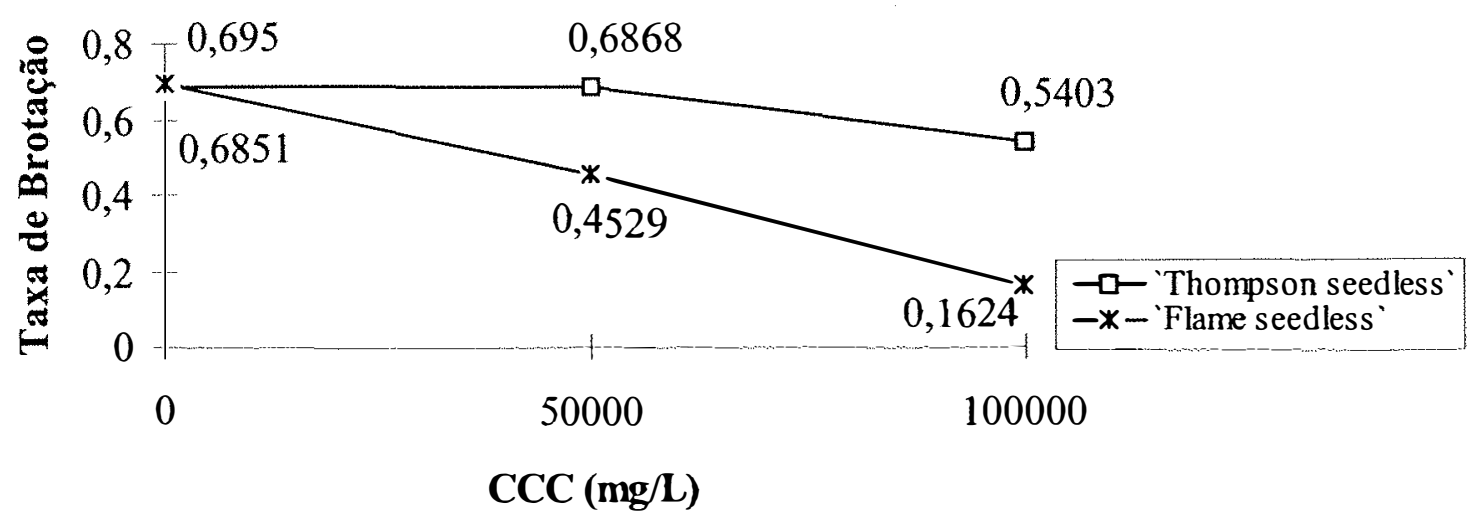

Figura 16 - Taxa de brotação (número de brotos/número total de gemas) verificada no segundo ciclo produtivo das $V$. vinifera (L.) 'Flame seedless' e 'Thompson seedless', sob efeitos dos tratamentos com CCC (0, 50000 e 100000 ppm). ESALQ-USP, Piracicaba, 2002.

Supõe-se, portanto, que a 'Flame seedless' possua níveis endógenos menores de giberelinas e, ou, de outros fitormônios de crescimento do que a 'Thompons seedless', sendo esta, talvez, uma das causas intrínsecas para a maior fertilidade da 'Flame seedless'. Powell (1987) relata que o uso de CCC prejudica a quebra de dormência das gemas da videira, pela inibição da biossintese de giberelinas.

\subsection{Conclusões}

Conclui-se, dentro das condições em que foi executado o experimento, que o chlormequat a $517,29 \mathrm{mg} \cdot \mathrm{L}^{-1}$, juntamente com a benzyladenina a $500 \mu \mathrm{M}$, tiveram efeito positivo sobre a fertilidade de gemas da 'Flame seedless'; porém, devido a queda nas taxas de brotação, observada pelo 
uso do chlormequat em altas concentrações, o comportamento vegetativo posterior de plantas tratadas com esses produtos deve ser verificado, assim como as futuras produções 


\section{CONCLUSÕES GERAIS}

Conclui-se, dentro das condições em que foram executados os experimentos, que:

a) As cultivares de uvas apirênicas Centennial seedless, Flame seedless e Thompson seedless comportam-se diferentemente aos tratamentos com CPPU e $\mathrm{GA}_{3}$ para o crescimento de bagas;

b) Aplicação de $100 \mathrm{mg} \cdot \mathrm{L}^{-1}$ de $\mathrm{GA}_{3}$ de forma isolada para 0 'Centennial seedless' e adicionada a $10 \mathrm{mg}^{-\mathrm{L}^{-1}}$ de CPPU para a 'Flame seedless' e 'Thompson seedless' foram as mais responsivas para o crescimento de bagas;

c) Aplicações de CPPU e GA ${ }_{3}$, destinadas ao crescimento de bagas prolongam o período normal da poda à colheita, verificado através da redução dos teores de sólidos solúveis totais no mosto das três cultivares;

d) A aplicação conjunta de Cycocel e Benzyladenina favorece a diferenciação floral, sendo mais efetiva para a 'Flame seedless' do que para a 'Thompson seedless';

e) Concentrações de Cycocel próximas a $500 \mathrm{mg} \cdot \mathrm{L}^{-1}$ propiciam crescimentos satisfatórios dos ramos, em diâmetro e comprimento, e uma melhor distribuição das gemas frutíferas ao longo dos mesmos;

f) Pelo efeito significativo da citocinina sobre a diferenciação das gemas, niveis acima $500 \mu \mathrm{M}$ de benzyladenina talvez promovam ainda mais a diferenciação das gemas da 'Flame seedless', sob condições especificas de cultivo; e a adoção de cultivares porta-enxertos, compativeis com o desenvolvimento vegetativo de cultivares copas apirênicas vigorosas enxertadas, provavelmente eleve a fertilidade das gemas; 
g) Logo, a interação Cycocel/Benzyladenina tem efeito positivo sobre a fertilidade das gemas de cultivares de uvas apirênicas; porém, devido a queda nas taxas de brotação- observada pelo uso do Cycocel em concentrações mais elevadas-, o desenvolvimento vegetativo e as produções futuras precisariam ser verificados para uma recomendação comercial. 


\section{REFERÊNCIAS BIBLIOGRÁFICAS}

ALBUQUERQUE, T.C.S. de. Absorção de macronutrientes pelos cultivares de videira Thompson seedless e Itália sob efeito de diferentes retardadores de crescimento e porta-enxertos. Piracicaba, 1998. 69p. Tese (Doutorado) Escola Superior de Agricultura "Luiz de Queiroz", Universidade de São Paulo.

ALMEIDA, G.V.B. Embalagem e comercialização de uva. In: BOLIANI, A.C.; CORREAA, L.S. (Ed.) Cultura de uvas de mesa: do plantio à comercialização. Ilha Solteira: UNESP, 2001. cap.15, p.281-316.

ALVARENGA, A.A.; ABRAHÃO, E.; REGINA, M.A.; ANTUNES, L.E.C.; PEREIRA, A. F. Origem e classificação botânica da videira. Informe Agropecuário, v.19, n.194, p.5-8, out. 1998.

AMARAL, A.L.do; OLIVEIRA, P.R.D.de; CAMARGO, U.A. Uvas de mesa apirênicas de resgate de embriões in vitro. In: CONGRESSO BRASILEIRO DE FRUTICULTURA, 15., Poços de Caldas, 1998. Resumos. Lavras:UFLA, 1998. p.727.

BERNARDO, S. Manual de irrigação. Viçosa: UFV, Impr. Univ., 1989. 596p. 
BORDELON, B.P.; MOORE, J.N. Promoting stenospermic grape seed trace development and germination with growth regulators. Journal of the American Society for Horticultural Science, v.119, n.4, p.719-726, 1994.

CAMARGO, U.A. Cultivares para a viticultura tropical no Brasil. Informe Agropecuário, v.19, n.194, p.15-19, out. 1998.

CAMARGO, U.A.; MANDELLI, F. Vênus - uva precoce para mesa. Bento Gonçalves: EMBRAPA, CNPUV, dez. 1993. 4p. (EMBRAPA. CNPUV. Comunicado Técnico, 13).

CAMARGO, U.A.; CZERMAINSKI, A.B.C.; MASHIMA, C.H. Fertilidade das gemas de cultivares de uvas apirênicas no Vale do Submédio São Francisco. In: CONGRESSO BRASILEIRO DE VITICULTURA E ENOLOGIA, 8., Bento Gonçalves, 1996. Programa e resumos. Bento Gonçalves: Embrapa Uva e Vinho, 1996. p.70.

CAMARGO, U.A.; MASHIMA, C.H; CZERMAINSKI, A.B.C. Avaliação de cultivares de uvas apirênicas no Vale do São Francisco. Bento Gonçalves: Embrapa Uva e Vinho, 1997. 8p. (Comunicado Técnico, 26)

CAMARGO, U.A.; RIBEIRO, V.G.; MAIA, J.D.G.; CZERMAINSKI, A.B.C. Efeito do cycocel e da desponta dos ramos sobre a fertilidade das gemas da cv. Thompson seedless. In: CONGRESSO BRASILEIRO DE VITICULTURA E ENOLOGIA, 9., Bento Gonçalves, 1999. Anais. Bento Gonçalves: Embrapa Uva e Vinho, 1999. p.142. 
CAMARGO, U.A.; DIAS, M.F.; DAL CONTE, A.F.; MANDELLI, F.; LOVATEL, J.L. Dona Zilá e Tardia de Caxias - uvas tardias para mesa. Bento Gonçalves: EMBRAPA, CNPUV, 1994. 4p. (EMBRAPA. CNPUV. Comunicado Técnico, 13).

CLELAND, R.E. Auxin and cell alongation. In: DAVIES, P.J. (Ed.) Plant hormones and their role in plant growth and development. Boston: Martinus Nijhoff, 1987. p.132-148.

COOMBE, B.G. Fruit set in grape vines: the mechanism of the CCC [(2chloroethyl) trimethylammonium cloride] effects. The Journal of Horticultural Science, v.45, p.415-425, 1970.

CRANE, J. C. Controlled growth of fig fruits by sinthetic hormone applications. Proceeding American Society for Horticultural Science, v.54, p. 102108, 1949.

CZERMAINSKI, A.B.C.; CAMARGO, U.A. Influência do ácido giberélico e do thidiazuron sobre a qualidade da uva 'Vênus'. In: CONGRESSO BRASILEIRO DE FRUTICULTURA, 15., Poços de Caldas, 1998. Anais. Poços de Caldas: Sociedade Brasileira de Fruticultura, 1998. p.747.

DIAZ, H.D.; MALDONADO, L.A. Forchlorfenuron effects on berry size and maturity of Perlette and flame seedless grapes. Proceedings Plant Growth Regulator Society American, v.19, p.123-128, 1992.

FNP CONSULTORIA \& COMÉRCIO. Agrianual 99: anuário de agricultura brasileira. São Paulo, 1998. p.507-519: Uva. 
FNP CONSULTORIA \& COMÉRCIO. Agrianual 2000: anuário de agricultura brasileira. São Paulo, 2000. p.535-545: Uva.

HUGLIN, P. Biologie et ecologie de la vigne Paris: Payot Lausanne, 1986. $372 p$.

JOUBLAN, M.J.P.; MERINO, H.R.; WILCHENS, E.R.; MEDINA, E. Efecto del CPPU y acido giberelico en frutos de vid cv. Moscatel Rosada, Agro Ciencia, v.11, n.2, p.119-127, 1995.

KENDE; H.; SITTON, D. The physiological significance of kinetin and gibberellin like root hormones. Annals of New York Academic Science, v.144, p.235243, 1967.

KOZLOWSKI, T.T.; KRAMER, P.J.; POLLARDY, S.G. The physiological ecology of woody plants. New York: Academic Press, 1990.655p.

LEÃO, P.C.S.; LINO JUNIOR, E.C.; SANTOS, E.S. Efeitos do CPPU e ácido giberélico sobre o tamanho de bagas da uva perlette cultivada no vale do São Francisco. Revista Brasileira de Fruticultura, v.21, p.74-78, 1999.

LEE, C.H.; HAN, D.H.; KIM, S.B. Effects of $\mathrm{GA}_{3}$ and Fulmet (KT-30) on fruit set and quality in 'Kyoho' grape. Journal of the Korean Society for Horticultural Science, v.37, p.686-690, 1996.

LILOV, D.; ANDONOVA, T. Cytokininis, growth, flower and fruit formation in Vitis vinifera. Vitis, v.15, p.160-170, 1976.

LOPES, A.S.; GUIDOLIN, J.A. Interpretação de análise do solo: conceitos e aplicações. São Paulo: ANDA, 1992. 50p. (Boletim Técnico, 2). 
MIELE, A.; DALL'AGNOL; A.; BIACHI, A. Efeito do CPPU no tamanho da baga e na composição da uva 'Itália'. In: CONGRESSO BRASILEIRO DE FRUTICULTURA, 15., Poços de Caldas, 1998. Anais. Poços de Caldas: Sociedade Brasileira de Fruticultura, 1998. p.742.

MOTOIKE, S.Y.; BRUCKNER, C.H.; CASALI, V.W.D.; CARDOSO, A.A. Cloreto de clorocolina (CCC) influenciando a fertilidade das gemas da videira (Vitis vinifera L.) cv. Itália. Revista Ceres, v.43, p.86-92, 1996.

MULLINS, M.G.; BOUQUET, A.; WILLIANS, L.E. Biology of the grapevine. New York: Cambridge University Press, 1992. 239p.

MUÑOZ, I. El cultivo de la uva de mesa: algunos aspectos de manejo como fatores de calidad. Santiago: Instituto de Investigaciones Agropecuarias Estacion Experimental La Platina, 1987. 36p.

NICKELL, L.G. New plant growth regulator increases grape size. Proceedings Plant Growth Regulator Society of America, v.12, p.1-7, 1985.

OLIVEIRA, P.R.D.de; CAMARGO, U.A. Recuperação de embriões oriundos de cruzamentos entre cultivares de uvas apirênicas. In: CONGRESSO BRASILEIRO DE VITICULTURA E ENOLOGIA, 7., Bento Gonçalves, 1993. Anais. Bento Gonçalves: Embrapa Uva e Vinho, 1993. p.24.

PANS-PEST ARTICLES AND NEWS SUMMARIES: a review of practical uses of Cycocel plant growth regulant. Cyanamid International, v.19, n.1, p.87-92, Mar. 1973.

PIRES, E.J.P. Emprego de Reguladores de Crescimento em Viticultura Tropical. Informe Agropecuário, v.19, n.194, p.40-43, out. 1998. 
POMMER, C.V. Uvas sem sementes. O Agronômico, v.47, n.50, p.38-39, 1998.

POMMER, C.V. O melhoramento de plantas no Instituto Agronômico. Campinas: Instituto Agronômico, 1993. p.489-524: Uva.

POMMER, C.V.; TERRA, M.M.; PIRES, E.J.P.; PASSOS, I.R.S. Indução de apirenia por estreptomicina em uva 'Itália'. Revista Brasileira de Fruticultura, v.14, n.2, p.195-200, 1992.

POMMER, C.V.; TERRA, M.M.; PIRES, E.J.P.; PASSOS, I.R.S.; MARTINS, F.P. Introdução das cultivares de uva de mesa 'Fantasia' e 'Ruiva' no Brasil. Scientia Agricola, v.56, n.1, p.247-253, 1999.

POWELL, L.E. Hormonal aspects of bud and seed dormancy in temperate-zone woody plants. HortScience, v.22, p.845-850, 1987.

REDDY, N.N.; PRAKASH, G.S. Effects of different rootstocks on bud fruitfulness in 'Anab-e-Shari' grape. Journal of Maharashtra Agricultural Universities, v.15, n.2, p.218-220, 1990.

REMATALES, J.; BANGERTH, F.; COOPER, T.; CALLEJAS, R. Effects of CPPU and $\mathrm{GA}_{3}$ on fruit quality of Sultanina table grape. Acta Horticulturae, n.394, p.149-157, 1995.

REYNOLDS, A.G.; WARDLE, D.A.; ZUROWSKI, C.; LOONEY, N.E. Phenylureas CPPU and thidiazuron affect yield compnents, fruit composition, and storage potential of four seedless grape selections. Journal of the American Society for Horticultural Science, v.117, p.85-89, 1992. 
ROSIER, J.P.; CARBONNEAU, A. Influência do sistema de condução e do tipo de solo sobre o crescimento vegetativo da videira. Bragantia, v.54, n.1, p.135-145, 1995.

SANTOS NETO, J.A.R. Melhoramento da videira. Bragantia, v.14, p.237$267,1955$.

SANTOS NETO, J.A.R. Melhoramento da videira no Instituto Agronômico. Bragantia, v.23, n.6, p.700-710,1971.

SARIG, P.; ZUTKHI, Y.; LISKER, N.; SHKELERMAN, Y.; BEN-ARIE, R. Natural and induced resistance of table grapes to bunch rots. Acta Horticulturae, n.464, p.65-70, 1998.

SKENE, K.G.M. The relationship between the effects of CCC on root growth and cytokines levels in the bleeding sap of Vitis vinifera (L.). Journal of Experimental Botany, v.21, n.67, p.418-431, 1970.

SNIRIVASAN, C.; MULLINS, M.G. Reproductive anatomy of the grapevine (Vitis vinifera L.): origin and development of the Anlagen and its derivatives. Annals of Botany, v.38, p.1079-1084, 1976.

SNIRIVASAN, C.; MULLINS, M.G. Control of flowering in the grapevine (Vitis vinifera L.)- formation of inflorescences in vitro by isolated tendrils. Plant Physiology, v.61, p.127-130, 1978.

SNIRIVASAN, C.; MULLINS, M.G. Effects of temperature and growth regulators on formation of anlagen, tendrils and inflorescences in Vitis vinifera (L.). Annals of Botany, v.45, p.439-446,1980. 
SOUZA, J.S.I. de. Uvas para o Brasil. São Paulo: Melhoramentos, 1969. 456p.

SPIEGEL-ROY, P.; SAHAR, N.; BARON, J.; LAVI, U. In vitro culture and plant formation from grape cultivars with abortive ovules and seeds. Journal of the American Society for Horticultural Science, v.110, p.109-112, 1985.

SUGIURA, A; UTSUNOMIYA, N.; KOBAYASHI, A. Induction of inflorescences by CCC application on primary roots of grapevines. Vitis, v.15, p.88-95, 1976.

TERRA,M.M. Nutrição e adubação da videira. In: SIMPÓSIO BRASILEIRO SOBRE UVAS DE MESA, 1., Ilha Solteira, 2000. Anais. Ilha Solteira:UNESP, 2001. p.149-176.

TERRA, M.M.; PIRES, E.J.P.; NOGUEIRA, N.A.M. (Coord.) Tecnologia para produção de uva Itália na região noroeste do Estado de São Paulo. Campinas: CATI, 1998. 81p. (Documento Técnico, 97).

THIRMANN, K.V. Plant senescence: A proposed integration of the constituent process. In: THOMSON, W.W.; NOTHNAGEL, E.A. (Ed.) Plant senescence: its biochemistry and physiology. Rockville: American Society of Plant Physiologists, 1987. p.1-19.

TODA, F.M. Biologia da la vid: fundamentos biológicos de la viticultura. Madrid: Mundi-Prensa, 1991. cap.2, p.29-43: Sistemática de la vid y características de sus principales especies.

TOMER, N.S. Fruting potential and quality of 'Beauty seedless' grape (Vitis vinifera) with differential pruning on head system of training. Indian Journal of Agricultural Science, v.60, n.9, p.603-607, 1992. 
TOMER, N.S. Fruting potential and quality of 'Perlette' grape (Vitis vinifera) with differential pruning on head system of training. Indian Journal of Agricultural Science, v.23, n.5, p.327-331, 1990.

TOMER, N.S. Fruting potential and quality of 'Cardinal' grape (Vitis vinifera) with differential pruning on head system of training. Indian Journal of Agricultural Science, v.62, n.3, p.203-208, 1994.

TORRES, A.C.; CALDAS, L.S. Técnicas e aplicações da cultura de tecidos de plantas. Brasilia: ABCTP, EMBRAPA, CNPH, 1990. 433p.

WEAVER, R.J.; VAN OVERBEEK, J.; POOL, R.M. Effect of kinins on fruit set and development in Vitis vinifera. Hilgardia, v.35, p.181-201, 1966. 